OPEN ACCESS

Edited by:

Burkhard Kleuser,

University of Potsdam, Germany

Reviewed by:

Hridayesh Prakash,

Amity University, India

Elsa Anes,

University of Lisbon, Portugal

*Correspondence:

Bernhard Brüne

b.bruene@biochem.uni-frankfurt.de

Specialty section:

This article was submitted to Microbial Immunology,

a section of the journal

Frontiers in Immunology

Received: 30 April 2019

Accepted: 08 July 2019

Published: 19 July 2019

Citation:

Weigert A, Olesch $C$ and Brüne $B$ (2019) Sphingosine-1-Phosphate and Macrophage Biology-How the

Sphinx Tames the Big Eater.

Front. Immunol. 10:1706.

doi: 10.3389/fimmu.2019.01706

\section{Sphingosine-1-Phosphate and Macrophage Biology-How the Sphinx Tames the Big Eater}

\author{
Andreas Weigert ${ }^{1}$, Catherine Olesch ${ }^{1}$ and Bernhard Brüne ${ }^{1,2,3,4 *}$ \\ ${ }^{1}$ Faculty of Medicine, Institute of Biochemistry I, Goethe-University Frankfurt, Frankfurt, Germany, ${ }^{2}$ German Cancer \\ Consortium (DKTK), Partner Site Frankfurt, Frankfurt, Germany, ${ }^{3}$ Project Group Translational Medicine and Pharmacology \\ TMP, Fraunhofer Institute for Molecular Biology and Applied Ecology, Frankfurt, Germany, ${ }^{4}$ Frankfurt Cancer Institute, \\ Goethe-University Frankfurt, Frankfurt, Germany
}

The sphingolipid sphingosine-1-phosphate (S1P) is produced by sphingosine kinases to either signal through intracellular targets or to activate a family of specific G-protein-coupled receptors (S1PR). S1P levels are usually low in peripheral tissues compared to the vasculature, forming a gradient that mediates lymphocyte trafficking. However, S1P levels rise during inflammation in peripheral tissues, thereby affecting resident or recruited immune cells, including macrophages. As macrophages orchestrate initiation and resolution of inflammation, the sphingosine kinase/S1P/S1P-receptor axis emerges as an important determinant of macrophage function in the pathogenesis of inflammatory diseases such as cancer, atherosclerosis, and infection. In this review, we therefore summarize the current knowledge how S1P affects macrophage biology.

Keywords: sphingosine-1-phosphate, macrophages, macrophage polarization, cancer, atherosclerosis, infection, inflammation

\section{INTRODUCTION}

In 1887, Metchnikoff published work on the nature host cells combating bacterial infection. He suggested the large cells he and other before him had observed taking up whole cells or cell fragments, to be named macrophages, as opposed to microphages (polymorphonuclear leukocytes) who specialized in combating bacteria (1). The term macrophage consequently is a composite of the Greek words makros, meaning large, and phagein, to eat, and denotes big eating cells. Today we are aware that macrophages are more than just big eaters, playing a multitude of crucial roles in development and maintaining adult tissue homeostasis. To be able to fulfill these roles, they command an enormous sensory repertoire to recognize cues suggesting endangered or disturbed homeostasis. One of these cues is the sphingolipid S1P that is produced during inflammation and upon tissue damage. Sphingolipids were named after the Sphinx by J. L. W. Thudichum in 1884 due to the enigmatic biochemical properties of their common backbone, the alcohol sphingosine. The Sphinx in Greek mythology poses riddles to travelers and kills them if they fail to answer correctly, whereas in Egyptian mythology the Sphinx is a rather benevolent guardian of sacred sites. Like the enigmatic Sphinx, S1P affects macrophage biology in different, sometimes antithetical ways. Here, we review the interaction of the sphinx and the big eater. We start with an introduction of the protagonists and their role in inflammation and tissue homeostasis. Next, we summarize the current knowledge on molecular mechanisms how S1P attracts macrophages and determines their survival, followed by reviewing how S1P affects the signature functions of macrophages, 
i.e., phagocytosis and the regulation of inflammation. Finally, we discuss how these S1P-dependent mechanisms affect macrophage function in pathological settings.

\section{MORE THAN BIG EATERS-MACROPHAGE FUNCTION IN HOMEOSTASIS AND DISEASE}

Macrophages are ubiquitous, yet diverse tissue-resident immune cells, involved in maintaining tissue integrity and function. They sense and actively respond to disturbances in tissue homeostasis by initiating, but also resolving inflammation $(2,3)$. The diverse functions of macrophages are tissues-specific and range from basic tasks, such as rearranging the extracellular matrix and taking up and recycling cellular and molecular debris, to highly specialized functions such as controlling tissue innervation or promoting conductance in the heart by modulating electrical properties of cardiomyocytes (3-6). Upon tissue injury, macrophages recognize new molecular patterns from dead cells or invading microorganisms. In turn, this mounts an immune response, e.g., by recruiting new inflammatory cells to the site of tissue disturbance. Once a noxa is cleared with the help of resident and recruited macrophages, macrophages participate in removing (dead) inflammatory cells by phagocytosis. At the same time they contribute to restore the tissue by promoting angiogenesis and reparative signaling in stroma and parenchyma (7-10). Their ability to cope with the changing demands during an acute inflammatory reaction suggests a remarkable plasticity.

Macrophage function is, to a large extent, dictated by the dominating microenvironment, rather than genetic imprinting. In tissues, macrophages have different developmental origins (11-13). They can be derived from early hematopoiesis in the yolk sac (11-17) or the fetal liver, without transitioning through a monocytic intermediate stage $(16,17)$. Post-natally, macrophages may derive from hematopoietic stem cell-derived monocytes from the bone marrow $(18,19)$. Tissue-resident macrophages of embryonic origin often self-renew by insitu proliferation, whereas monocyte-derived macrophages are frequently, but not always, short-lived and continuously replaced (11-14, 20). During depletion of the resident macrophage pool upon e.g., inflammation or experimental means, monocytes or other macrophage progenitors readily integrate into the tissue macrophage pool and become self-renewing cells $(11,12,14,20$, 21). Moreover, transplantation of mature macrophages between tissues alters their transcriptional program to fit the recipient tissue macrophage pool (20). Finally, distinct macrophage subsets, partly of similar developmental origin, are found in specialized niches within one tissue (22-25).

The notion that the microenvironment determines macrophage function is further supported by identifying tissue-specific transcription factors that are required to establish tissue macrophage identity. All macrophages depend on the lineage-determining transcription factor PU.1, whose expression is triggered by colony stimulating factor-1 (CSF1) or interleukin (IL-)34 (IL-34), which signal through colony stimulating factor-1 receptor $(26,27)$. Moreover, the transcription factor ZEB2 is required for macrophage identity across a number of tissues (28). On top of this basic transcriptional program, tissue-specific transcriptional regulators were identified that are activated downstream of tissue-enriched molecular cues. These include SPI-C in progenitors of red pulp and bone marrow macrophages (29), GATA6 in peritoneal macrophages $(30,31)$, peroxisome proliferator-activated receptor (PPAR) in alveolar macrophages (32), SMAD transcription factors and myocyte-specific enhancer factor 2c (MEF2c) in microglia $(33,34)$, liver $\mathrm{x}$ receptor $(\mathrm{LXR} \alpha)$ in Kupffer cells, as well as Runt-related transcription factor 3 (RUNX3) in intestinal macrophages and Langerhans cells $(20,35)$.

Despite these lineage- and tissue-imprinted molecular programs, macrophages retain a remarkable degree of plasticity to respond to the appearance of new molecular cues indicative of a disturbed homeostasis. These cues are sensed by a repertoire of receptors on macrophages and activate transcriptional enhancers or repressors, generating a large number of possible activation states (36-39). A considerable body of research aimed at defining discrete macrophage polarization states in vitro by using sets of specific molecular or functional markers, which are thought to serve as predictors of macrophage function in living organisms $(36,40-42)$. Frequently used is the M1/M2 nomenclature, where M1 macrophages are stimulated with interferon- $\gamma$ (IFN- $\gamma$ ) and lipopolysaccharide (LPS) to mimic a condition arising during type 1 inflammation (defense against microbial infection), whereas M2 macrophages are stimulated with the TH2 cytokines IL-4 or IL-13 to mimic conditions of type 2 inflammation (helminth infection). Specific marker signatures have been assigned to these cells. M1 macrophage activation creates an anti-microbial, pro-inflammatory cell with a transcriptional signature defined by activation of nuclear factor kappa-light-chain-enhancer of activated B cells (NF-кB), signal transducer and activator of transcription 1 (STAT1) and interferon regulatory factor 5 (IRF 5) (43, 44). M1 or classically activated macrophages produce pro-inflammatory mediators such as tumor necrosis factor- $\alpha$ (TNF- $\alpha$ ), IL- $1 \beta$, IL-6, and IL-12, generate reactive oxygen and nitrogen species (ROS/RNS), and activate $\mathrm{T}$ cells to produce type 1 cytokines. M2 or alternatively activated macrophages display activation of the transcription factors STAT6 and IRF4 to express specific chemokines including CCL17 and CCL18, phagocytic receptors such as the mannose receptor CD206, arginases (ARG1/2) to limit NO production, and mediators that modulate the extracellular matrix. All of them are originally induced to combat extracellular parasites $(36,39,44-46)$. The M1/M2 nomenclature is useful, although naturally limited since macrophages in a tissue never face M1 or M2-specific stimuli. In fact, IL-4 and IFN- $\gamma$ are often produced simultaneously during inflammation (47). In analogy to T cells, IL- 4 , and IFN- $\gamma$, besides inducing discreet transcriptional outputs, mutually suppress the impact of the corresponding signaling pathway to affect the macrophage phenotype. IL-4 suppresses enhancer regions in a large set of inflammatory genes directly via STAT6 (48), while IFN- $\gamma$ induces a loss of enhancer binding by the transcription factor MAF in M2 genes to reduce chromatin accessibility (49). Even 
when supplied together in cell culture, IFN- $\gamma$ and IL-4 mutually inhibited epigenomic and transcriptional changes induced by each cytokine alone, while allowing the expression of core functional parameters such as IFN- $\gamma$-triggered antiviral genes (47). Moreover, macrophage polarization by IFN- $\gamma$ or IL-4 appears to be a transient rather than a stable process $(47,50,51)$, which makes sense when different functional needs arise during the course of an inflammatory reaction. Therefore, "pure" M1 or M2 macrophages will not be found in a complex environment, and claiming distinct functions from a small set of markers expressed by macrophages in a tissue needs to be approached carefully. Nevertheless, understanding mechanisms that regulate macrophage plasticity is of importance, since dysregulation of macrophage activity is connected to human pathologies including major causes of premature death such as infection, atherosclerosis, fibrotic diseases, and cancer $(3,37)$.

\section{ENTER: THE SPHINX-S1P AND ITS RECEPTORS IN IMMUNITY}

Sphingosine-1-phosphate (S1P) is a biologically active lipid mediator being produced in and affecting macrophages. With central roles of macrophages during inflammation and cancer the sphere of S1P actions touches ground under a number of physiological as well as pathological settings. Production, degradation, and biological actions of S1P in the mammalian system have been reviewed in depth (52-58) and are only briefly recapitulated. Central to sphingolipid metabolism is ceramide, which is a hub for sphingolipid synthesis and degradation (59). De novo synthesis of ceramide starts by condensation of serine and palmitoyl-CoA to form 3-keto-dihydrosphingosine, which is subsequently reduced to dihydrosphingosine and $\mathrm{N}$-acylated to form a large group of dihydroceramides (60). A desaturase then produces corresponding ceramides. Ceramides can either be phosphorylated, or glycosylated to form glucosylceramides, which are processed and exposed at the plasma membrane as glycosphingolipids. Alternatively, ceramides can be converted to sphingomyelin, also being incorporated into the outer cell membrane. There, sphingomyelin can be attacked by neutral or acidic sphingomyelinase and converted back to ceramide. In turn, ceramides are cleaved by ceramidases to generate sphingosine, which gets phosphorylated by sphingosine kinase1 (SPHK1) or-2 (SPHK2) to form S1P $(55,61)$. S1P can be transformed in the salvage pathway via sphingosine back to ceramide or irreversibly degraded by S1P lyase (SGPL1) to hexadecenal and phosphoethanolamine. S1P, produced at the plasma membrane, can be exported from cells by ATPbinding cassette (ABC) transporters or spinster 2 (Spns2) (62, 63). Once outside cells, S1P is recognized by a family of five distinct G-protein coupled receptors (S1PR1-5) that initiate autocrine, "inside-out," or paracrine signaling (64). Cell typeselective expression of distinct S1P receptors and their coupling to different G-alpha subunits allows S1P to exert a multitude of signaling qualities (53). S1P can also signal intracellularly via several less generalized and commonly accepted targets (65-67), which also plays a role during macrophage activation.
Macrophages express all five S1P receptors, albeit receptor expression varies among different macrophage subtypes and seems related to distinct functional properties (67). S1P receptors belong to a family of seven helix transmembrane G-protein coupled receptors (GPCR), linked to either $G_{i}, G_{q}$, and/or $G_{12 / 13}$. Concomitantly, directly tied signaling pathways including small GTPases, phospholipases, PI3K, or adenylyl cyclase are affected, which in turn initiate a myriad of diverse signals. Specific G-protein-coupled receptors (S1PR) signaling is commonly connected to cell migration, proliferation, and differentiation, with individual S1P receptors partly mediating convergent and partly mediating antithetic responses (68). For instance, S1PR1, coupling to $G_{i}$ promotes the migration of lymphocytes, while S1PR2, which couples to $G_{i}, G_{q}$, and $G_{12 / 13}$, restricts migration (69). This reciprocal interaction regulates among others B cell localization in lymphatic organs. On the other hand, S1PR1/2 and 3 , the latter also coupling to $G_{i}, G_{q}$, and $G_{12 / 13}$, appear to jointly coordinate vascular development during embryogenesis in mice and zebrafish $(70,71)$.

$\mathrm{S} 1 \mathrm{P}$ is a prototypical molecular signal that is induced upon disturbance of tissue homeostasis. Normally, its levels in tissues are too low to activate specific receptors, with the exception of the circulation, where S1P levels reach nano- to micromolar concentrations (72). However, during inflammation S1P levels rise and are sensed, among others cells by macrophages. As macrophages are exposed to multiple signals from their environment, which allows them to adjust their output repertoire under homeostatic, inflamed, or regenerative conditions, S1P production, S1P receptor expression and/or signaling might add to the complexity of their functional properties. On the following pages we therefore summarize the impact of the $\mathrm{S} 1 \mathrm{P}$ signaling system on macrophage responses (summarized in Figure 1), and discuss if modulation of this system might be therapeutically attractive.

\section{ATTRACTING THE EATER-S1P AND MACROPHAGE HOMEOSTASIS}

In the last years it became evident that S1P plays an important role in tissue surveillance by recruiting immune cells and modulating their life-span (65). Consequently, S1P affects macrophage-driven tissue homeostasis by, among others, mediating macrophage differentiation, migration and survival. $\mathrm{S} 1 \mathrm{P}$, as shown for various other cell types, also serves in macrophages as an anti-apoptotic signal. It is suggested that $\mathrm{S} 1 \mathrm{P}$ prevents caspase-induced apoptosis of macrophages by inducing the expression of anti-apoptotic proteins such as B-cell lymphoma 2 (Bcl-2) and B-cell lymphoma extra-large (Bcl-XL) through the activation of phosphoinositide-3-kinase (PI3K), extracellular-signal regulated kinase (ERK)1/2 and $\mathrm{Ca}^{2+}$ signaling pathways or changing the cellular balance of ceramide to sphingosine or $\operatorname{S1P}(58,73,74)$. A more recent study showed that S1P acted as an anti-apoptotic component of high-density lipoprotein (HDL) by inducing inhibitor of apoptosis (IAP) family member survivin via STAT3 in THP1 and RAW264.7 macrophages (75). This was blocked by 


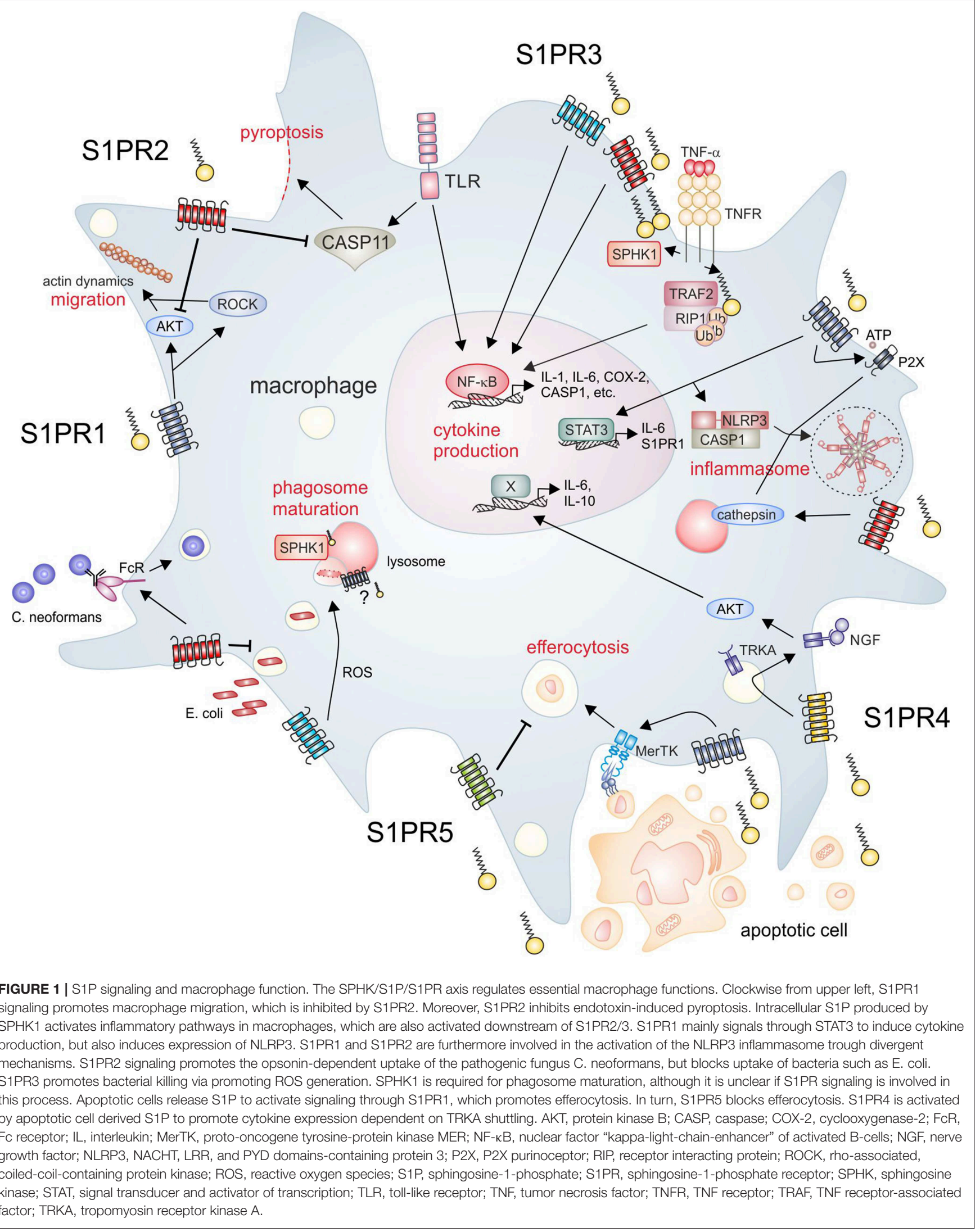


antagonists against S1PR2/3, indicating cooperative signaling by S1PR2/3 under these conditions (75). Reduced caspaseinduced cell death of macrophages by S1P may extend beyond apoptosis. S1PR2 signaling was demonstrated to reduce caspase11 protein expression in peritoneal macrophages, thereby limiting macrophage pyroptosis (76). Shifting the cellular balance of ceramide to sphingosine/S1P toward the latter seems not only to be important for macrophage survival but also plays a role during the differentiation of blood monocytes to macrophages. Monick et al. showed that during macrophage differentiation levels of acid ceramidase increased, which enhanced the lifespan of macrophages, most likely due to the conversion of ceramide to sphingosine, resulting in higher intracellular S1P levels (77).

For macrophages to maintain tissue homeostasis they not only need to regulate their number by survival, but they also have to be in the right place at the right time. Accordingly, S1P can also serve as a lipid attraction signal to guide macrophages to the sites of inflammation and tissue repair (78). It has been shown that S1P-dependent macrophage migration is strictly dependent on their S1PR profile. Thereby, S1PR1 signaling seems to be pro-migratory as shown for peritoneal macrophages involving Rho kinase and PI3K-Akt1 signaling and for bone marrow-derived macrophages (BMDM), stimulated by S1Penriched extracellular vesicles during hepatic lipotoxicity (79, 80). S1PR1 is also essential for post-inflammatory macrophage emigration as shown in a mouse model of resolving peritoneal inflammation, harboring a macrophage-specific deletion of S1PR1, which reduced emigration of macrophages from the site of inflammation (81). More recently it has been discussed that S1PR4 signaling may inhibit the pro-migratory actions of S1PR1 and that the S1PR1/S1PR4 ratio is important for the emigration of pro-inflammatory M1 macrophages from sites of inflammation. It was demonstrated that M1 macrophages exhibit a higher S1PR1/S1PR4 ratio than M2 macrophages (82). However, further studies for example inhibiting S1PR1 and -4 individually in macrophages are needed to clarify the functional role of the S1PR4 to S1PR1 counter-regulation during inflammation. In contrast to the pro-migratory actions of S1PR1, S1PR2 signaling was proposed to inhibit macrophage trafficking by stimulating cAMP production, thereby attenuating Akt phosphorylation, as demonstrated using S1PR2 knockout mice in a peritonitis model of acute inflammation (83). These findings exemplified the antithetic properties of S1PR1 and S1PR2 in immune cell migration. In support of this concept, chemotaxis of osteoclast precursors, with osteoclasts being bone macrophages, is reciprocally regulated by $\mathrm{S} 1 \mathrm{PR} 1 / 2$, which serves to fine-tune their localization in bones (84). However, Yang et al. proposed S1PR2/3 on BMDM to be pro-migratory, possibly due to the fact that both receptors share activation of similar signaling pathways involving PI3K and Ras-related C3 botulinum toxin substrate 1 (Rac1) (85). In the same study they excluded an involvement of S1PR1 in macrophage migration by stimulating BMDM with the selective S1PR1 inhibitor W146, which did not alter S1P-induced BMDM migration. This observation is rather contradictory to a number of studies discussed above, which clearly indicate a role for S1PR1 signaling in inducing macrophage migration. Macrophages may even switch their
S1PR profile toward S1PR1 to allow migration to the lymphatics, similarly to dendritic cells $(81,86)$. Since macrophages are the most plastic cells of the immune system, contradictory studies on macrophage-specific S1P receptor functions are most likely due to different S1PR expression profiles, sources and distinct in vitro macrophage differentiation protocols. Further studies are required to delineate under which circumstances signaling through S1PR1 and S1PR2 cooperate or oppose each other during macrophage migration. In summary, in order to maintain tissue homeostasis, macrophages need to survive under stress conditions and need to migrate to specific tissue sites. For these actions the S1P/S1PR signaling axis appears to be critical as the above mentioned studies suggest.

\section{PREPARING THE MEAL AND AIDING IN DIGESTION-IMPACT OF S1P ON PHAGOCYTOSIS}

Phagocytosis of pathogens or cellular debris is a key function of macrophages, as their name suggests. S1P has been shown to be involved in both, uptake of pathogens and cellular debris, i.e., dying cells. While these two processes occur via different molecular mechanisms, they both can be broken down into similar steps, i.e., recognition of the phagocytic material, phagosome formation, and phagosome content removal e.g., phagosome-lysosome fusion (87). S1P signaling participates in each of these three steps in macrophages.

S1P is produced by cells upon induction of apoptosis (88). It acts on macrophages to alter their functional phenotype, as outlined in the next paragraph. Moreover, S1P serves as a findme signal to attract phagocytes to the dying cell for removal (78). This system can be hijacked by Yersinia pestis, which triggers cell death in macrophages. The resulting S1P release serves to recruit further macrophages, which are then infected to promote spread of bacteria (89). Besides altering macrophage activation and promoting recruitment, recent data suggest an involvement of S1P in priming macrophages for uptake of cell debris (90). Apoptotic cell-derived S1P triggered erythropoietin (EPO) signaling in murine macrophages, which induced upregulation of phagocytic receptors, including CD36 and Mer tyrosine kinase (MerTK) (90). Accordingly, mice lacking the EPO receptor in myeloid cells showed delayed clearance of apoptotic cells and lupus-like autoimmune symptoms. Interestingly, not only S1P produced by dying cells appears to be involved in apoptotic cell phagocytosis (efferocytosis). Inhibition of SPHKs in macrophages by pharmacological inhibitors or cigarette smoke reduced efferocytosis in human THP-1 macrophages. Addition of exogenous S1P or the S1PR agonist FTY720 reversed cigarette smoke-induced inhibition of efferocytosis and promoted macrophage SPHK functionality (91). Accordingly, the S1P transporter SPNS2 was decreased in smoke-exposed bronchial epithelial mice, correlating with reduced efferocytosis (92). Unexpectedly, smoke exposure increased SPNS2 expression in alveolar macrophages and upregulation of the S1PR5 in alveolar macrophages was associated with impaired efferocytosis (92-95). Thus, S1P receptors may differ in their capacity to 
promote or inhibit efferocytosis and the S1P system in both, macrophages and dying cells appears to be involved in chronic obstructive pulmonary disease (COPD), which is induced by smoking and linked to impaired efferocytosis.

It remains unclear if $\mathrm{S} 1 \mathrm{P}$ only promotes efferocytosis by increasing phagocytic receptor expression, or whether S1P signaling may also participate in the actual engulfment machinery. So far, the picture is clearer when looking at pathogen uptake as S1P facilitates the expression of uptake receptors. The phagocytic receptor Fc $\gamma$ RII (CD32) is induced in human macrophages (96). This may require signaling through S1PR2, since S1PR2-deficient macrophages expressed significantly lower levels of Fc $\gamma$ RI, II, and III (97). Thereby, S1P triggered S1PR2-dependent phagocytosis of the pathogenic fungus Cryptococcus neoformans (C. neoformans) (97). Apparently, S1P promotes opsonin-dependent phagocytosis of pathogens. In contrast, S1PR2-deficient murine macrophages phagocytosed Escherichia coli (E. coli) more efficiently, which was attributed to reduced RhoA-dependent cell contraction, but increased formation of lamellipodial protrusions when S1PR2 was absent (98). Importantly, phagocytosis of E. coli occurred opsonin-independent, adding to the notion that S1P modulating effects on phagocytosis depend on the S1PR being triggered and the mechanism of uptake. E. coli phagocytosis relied on RhoA and therefore actin dynamics. Two earlier studies suggested that $\mathrm{S} 1 \mathrm{P}$ modulates actin assembly to promote phagosome formation. S1P promoted an ADP to ATP conversion and subsequent purinergic ligand-gated ion channel P2X7 signaling in the phagosome lumen or extracellularly, both promoting actin assembly at the plasma membrane in murine macrophages $(99,100)$. Moreover, S1P triggered ATP release from RAW264.7 macrophages by activating volume-regulated anion channels downstream of S1PR1. This required the actin cytoskeleton, suggesting that S1PR1 signaling may affect the actin cytoskeleton to induce a feed-forward mechanism involving purinergic signaling to promote phagosome formation and maturation. A critical function for S1P in phagosome maturation is supported by the observation that exogenous S1P promotes the interaction of phagosomes with the actin cytoskeleton to allow trafficking of the phagosome toward lysosomes for lysosomal fusion (101). Phagolysosome generation in Mycobacterium tuberculosis ( $M$. tuberculosis) infected human macrophages required exogenous S1P-dependent phospholipase D activity, thereby promoting killing of $M$. tuberculosis (102). Besides $M$. tuberculosis, exogenous S1P was also shown to enhance killing of other mycobacteria by macrophages (103). However, S1PR3 was implicated in promoting phagosome maturation in mouse macrophages, since S1PR3-deficient peritoneal macrophages treated with heat-killed $E$. coli showed reduced phagolysosome fusion (104). Besides exogenous S1P, intracellular S1P formation was required for killing of mycobacteria by macrophages. Targeting SPHK1 genetically or pharmacologically rendered murine RAW 264.7 macrophages sensitive to infection with $M$. smegmatis, whereas overexpression of SPHK1 promoted killing. This was accompanied by SPHK1-dependent expression of the late phagosome marker LAMP2, but also SPHK1-dependent NO formation (105). Strikingly, it was further shown that intracellular M. tuberculosis blocked phagosome maturation by impairing SPHK activity (106). M. tuberculosis is known to block its killing in fused acidic phagolysosomes. Ingestion of dead, but not living M. tuberculosis induced SPHK1 sphingosine kinase activity and translocation to nascent phagosomes in human macrophages, followed by an increase in intracellular $\mathrm{Ca}^{2+}(106,107)$. SPHK1 translocation in itself was $\mathrm{Ca}^{2+}$ dependent as suggested by the use of an intracellular $\mathrm{Ca}^{2+}$ chelator. Besides mycobacteria, a role for SPHK1 in controlling C. neoformans infection was suggested (108). In particularly, SPHK1 restricted intracellular C. neoformans growth in alveolar macrophages and also restricted macrophage infection with Leishmania donovani (109), although it is unclear if this was dependent on phagolysosome formation.

Collectively these data indicate that intracellular as well as extracellular S1P, presumably via S1PR signaling, has microbicidal potential by modulating pathogen uptake, phagosome formation, maturation, and phagolysosome fusion. Moreover, S1PR3 activation on mouse macrophages promoted ROS formation and therefore killing of ingested bacteria (104). The notion of a crucial role of the S1P system in pathogen control is underscored by observations that microbial SGPL1 promotes their survival in macrophages. SPGL1 from Burkholderia pseudomallei was required for phagosome evasion, presumably by lowering S1P levels, as indicated by observations that S1P and S1PR1 agonists increased bacterial content in lysosomes and reduced their intracellular survival (110). Moreover, SGPL1 from Legionella pneumophila promoted intracellular pathogen survival by blocking autophagy through disrupting sphingolipid metabolism, thereby again preventing lysosomal killing of pathogens (111). Therefore, a number of different pathogens have developed strategies to target the S1P system and to evade intracellular degradation in lysosomes $(106,110,111)$.

\section{ADDING FLAVOR-S1P AND MACROPHAGE POLARIZATION}

During recent years it became apparent that the impact of $\mathrm{S} 1 \mathrm{P}$ on the macrophage phenotype is not restricted to the M1/M2 paradigm. Rather, S1P modulates macrophage responses according to the local environment, the compartmentalization of $\mathrm{S} 1 \mathrm{P}$, i.e., intra vs. extracellular $\mathrm{S} 1 \mathrm{P}$, and the $\mathrm{S} 1 \mathrm{P}$ receptors activated on cells. Consequently, S1P not only promotes the production of M2 but also of M1-associated macrophage markers.

Intracellular S1P produced by SPHK1, likely at the plasma membrane, was suggested as a cofactor involved in inflammatory macrophage activation. Inflammatory macrophage activation is triggered by microbial components such as LPS, with or without type 1 lymphocyte-derived IFN- $\gamma$. As a consequence, TNF- $\alpha$ is rapidly produced by mechanisms including proteolytic shedding from the plasma membrane (112), and increasing mRNA stability (113). TNF- $\alpha$ then binds to its cognate receptors to feedforward promote canonical NF- $\mathrm{B}$ activation, which requires TNF receptor-associated factor 2 (TRAF2) to polyubiquitinate receptor interacting protein 1 (RIP1). SPHK1 was shown to be activated downstream of TNF receptor activation and to 
physically interact with TRAF2. SPHK1-derived S1P then acted as cofactor for TRAF2, allowing polyubiquitination of RIP1 (114, 115). Also IL-1 signaling, another feed-forward NF$\kappa \mathrm{B}$ activator following microbial encounter, required SPHK1dependent S1P as an intracellular cofactor (116). Besides TNF and IL-1 $\beta$, SPHK1 is also rapidly activated downstream of other inducers of inflammatory macrophage activation, including LPS (117-119), and LPS in combination with palmitate (120), although it is unclear if SPHK1-derived S1P acts as a cofactor for intracellular LPS signaling. Stimulation of human THP-1 macrophages or mouse microglia with LPS required SPHK1 activity to produce IL-6, IL- $1 \beta$, TNF- $\alpha$, and/or NO $(117,118)$, whereas SPHK1 was dispensable for LPS, but not LPS/palmitateinduced IL- 6 production, and TNF- $\alpha$ induced cyclooxygenase (COX)-2 expression in mouse RAW264.7 macrophages (119, 120). Accordingly, SPHK1-deficient mice showed decreased joint inflammation in a model of murine TNF- $\alpha$-induced arthritis (121). In contrast, SPHK1-deficient mice were not protected from collagen-induced arthritis and thioglycollatetriggered peritonitis, indicating that SPHK1 activation may be restricted to specific inflammatory stimuli (122). It is important to note that mouse macrophages lacking both SPHK isoforms did not show any alterations in cytokine production in vitro and induction of LPS or thioglycollate-induced inflammation in vivo (123). This may be explained by divergent functions of SPHK isoforms in inflammation, as has been noted in a model of inflammation-induced colon cancer, where SPHK2 ablation triggered SPHK1-dependent cytokine production in myeloid cells and thus promoted M1 macrophage activation (124). The exact role of SPHK2 in macrophage activation is, however unclear. Besides promoting M1-like cytokine production, an increase in anti-inflammatory macrophages was reported in SPHK2-deficient obstructed kidneys. Treating SPHK2-deficient murine BMDM with IL-4 or IL-13 induced a more pronounced M2 profile compared to wild type macrophages (125). Thus, macrophage SPHK2 may restrict M1 as well as M2 activation. Further mechanistic investigations will be required to support this claim.

Despite its role in providing $\mathrm{S} 1 \mathrm{P}$ as an intracellular cofactor, SPHK1 activation by inflammatory triggers may increase extracellular S1P, thereby provoking S1P receptor activation. The accompanying cell response appears to be highly context and receptor-dependent. Initial studies in human alveolar macrophages suggested that $\mathrm{S} 1 \mathrm{P}$ alone induced NADPH-oxidase (NOX)2-dependent production of ROS (126) to promote IL-1 $\beta$ and TNF- $\alpha$ production by murine peritoneal macrophages (127). These findings were recently supported by a study suggesting that S1P stimulation of murine BMDM triggered the expression of inflammatory markers including TNF- $\alpha$, CCL2, and inducible NO-synthase (iNOS), which were suppressed by targeting S1PR2/3 and downstream c-Jun N-terminal kinase (JNK) activation, again exemplifying the cooperate potential of S1PR2/3 signaling in macrophages (128). Increased iNOS expression was also observed when murine BMDM were subjected to LPS/IFN- $\gamma$ treatment with the addition of exogenous S1P (82). The impact of S1PR3 on promoting inflammatory macrophage activation was substantiated in studies using murine microglia in vitro and a model of brain ischemia. A S1PR3 specific antagonist and siRNA-mediated depletion of S1PR3 reduced LPS-triggered expression of TNF- $\alpha$, IL-6, and IL-1 $\beta$ (129). Moreover, LPSinduced expression of inflammatory genes such as iNOS, COX2 , IL-1 $\beta$, IL-6, and TNF- $\alpha$ in primary peritoneal macrophages was reduced by an S1PR3 antagonist (130). S1PR3 may therefore be viewed as an inflammatory receptor in macrophages. While the majority of inflammatory macrophage markers depend on transcriptional induction, IL-1 $\beta$ maturation and release in response to microbial stimulation requires expression and activation of inflammasomes in macrophages, including the NLRP3 inflammasome, a protein complex consisting among others of the eponymous NLRP3 and inflammatory caspase1 (131). S1P was shown to selectively promote the expression of NLRP3 among inflammasome components downstream of S1PR1 in tumor-associated macrophages (TAM), as well as LPS-stimulated mouse BMDM and human primary monocytederived macrophages (132). Besides NLRP3 expression, S1PR1 was also involved in promoting ATP release at least in a murine macrophage cell line, which is one of the triggers of NLRP3 inflammasome activation (133). Another activating mechanism of the NLRP3 inflammasome, the release of cathepsin B from lysosomes, was associated with S1PR2 signaling (134). Accordingly, levels of IL-1 $\beta$ and IL-18, which are inflammasome dependent, were reduced in the serum of S1PR2deficient mice challenged with endotoxin (135). Thus, S1P via S1PR1/2, although not through converging signaling pathways, may cooperate toward NLRP3 inflammasome assembly and activation, promoting IL- $1 \beta$ maturation (136). Interestingly, the effect of S1PR1 on NLRP3 expression suggests that S1PR1 operates independently of canonical NF- $\kappa$ B or classical mitogenactivated protein kinase (MAPK) cascades triggered downstream of toll-like receptor (TLR), TNF receptor, or IL-1 receptor activation. Along these lines, antagonism of S1PR3, which generally reduced LPS-triggered inflammation in peritoneal macrophages, restricted caspase-1 but not NLRP3 expression (130). Indeed, S1P blocked LPS-dependent stimulation of NF$\kappa \mathrm{B}$ activation and downstream production of inflammatory cytokines such as TNF- $\alpha$ in murine and human macrophages (137-139), and to attenuate TLR2-dependent NF- $\mathrm{B}$ activation in human monocytes (140). Also, S1PR1 triggered STAT3 signaling to promote induction of heme oxygenase-1 (73), as well as IL-6. Particularly, S1PR1 signaling promoted IL-6 production in a STAT3-dependent feedback loop, where IL-6 induced S1PR1 expression in mouse macrophages in vitro, in a model of sickle cell disease, and in dextran sodium sulfate (DSS)-induced colitis $(124,141)$. In RAW264.7 macrophages S1PR1 but also S1PR2 were involved in LPS and palmitate-induced IL-6 production (120). Moreover, S1PR1 signaling increased ARG1 activity in mouse macrophages to block the production of $\mathrm{NO}$, which was induced by microbial stimuli in concert with IFN- $\gamma$, although the impact of STAT3 signaling in this context was not tested (137). S1P alone or in the supernatant of apoptotic tumor cells also elevated prostaglandin $\mathrm{E}_{2}\left(\mathrm{PGE}_{2}\right)$ production, which required stabilization of COX-2 mRNA, likely via S1PR1 (119, 142, 143). These data suggest that S1PR1 may limit microbial-induced inflammatory pathways such as canonical NF- $\kappa$ B activation, but 
induces inflammatory mediators such as IL-1, IL-6, and PGE 2 under conditions characterized by low-grade inflammation, as found e.g., in tumors $(124,132)$.

The role of S1PR2 in macrophage activation appears less clear. While it was associated with inflammasome activation as outlined above, it was required for induction of ARG2 in RAW 264.7 macrophages stimulated with apoptotic cells (144), which required the transcription factor cAMP response element-binding (CREB). S1P also augmented cAMP levels in $\mathrm{PGE}_{2}$ or isoproterenol-stimulated RAW 264.7 macrophages through S1PR2 (145). Therefore, S1PR2 signaling is coupled to increasing cAMP levels in macrophages, which was connected to resolution of inflammation (146). Pro-resolving macrophages are also generated by the interaction with apoptotic cells, which might provide a connection between apoptotic cell-derived S1P and resolution of inflammation by establishing resolution type macrophages downstream of S1PR2. However, this hypothesis remains to be tested. The impact of S1PR4 and S1PR5, whose expression is low in most macrophages, toward macrophage polarization is largely unclear. Activation of S1PR4 primed apoptotic tumor cell-stimulated macrophages for signaling via the nerve growth factor receptor TrKA, which induced among others IL-6 and IL-10 expression (147). It is unclear if S1PR4 activation has a similar effect under other conditions. S1PR5 was so far only connected to impaired phagocytosis as outlined above.

In conclusion, SPHK activity and S1PR signaling emerge as important regulators of macrophage polarization, although the impact of some components of this machinery such as SPHK2, S1PR4, and S1PR5 needs to be tested in the future. Since macrophages are implicated in the development of inflammatory diseases, altered functional macrophage responses by the S1P system are expected to affect such conditions. This will be outline in the next chapter.

\section{THE EATER GONE ROGUE-S1P AND MACROPHAGE FUNCTION IN DISEASE}

\section{Cancer}

Already in 1863, Rudolf Virchow observed that tumors are heavily infiltrated by leukocytes and proposed that a chronic inflammatory milieu promotes cancer initiation and progression (148). In the last decades it became clear that the immune system and its effector cells exhibit a multifaceted role in carcinogenesis. The immune system is capable of tumor rejection but paradoxically also able to promote cancer progression, which is mediated by the tumor microenvironment triggering immune tolerance $(149,150)$. One group of effector cells that contribute to the multifaceted role of the immune system in carcinogenesis are tumor-associated macrophages (TAM), which depending on their phenotype contribute to a pro- or anti-tumor immune response. Whereas, TAM expressing M1 markers produce proinflammatory cytokines and ROS that are crucial for tumor cell killing, TAM expressing M2 markers suppress an anti-tumor immune response by producing anti-inflammatory cytokines, which causes immune suppression and in the long term tumor outgrowth (151-153).
Tumor cells themselves can produce factors that activate and shape a pro-tumor M2-like TAM phenotype during tumor escape, provoking tumor progression including metastasis. One of the factors produced by tumor cells is S1P. S1P, already discussed as a pro-survival factor, exhibits pro-tumor functions by adding to tumor cell transformation, survival, migration, and neovascularization in different cancer types such as breast, colon and prostate cancer (154). We previously showed that S1P is released by apoptotic breast cancer cells and polarizes macrophages toward a M2-like phenotype, characterized by reduced TNF- $\alpha$, IL-12 but increased IL8 and IL-10 secretion (138). Tumor cell specific secretion of S1P, concomitant macrophage M2-like polarization, and subsequent tumor growth was recapitulated in a more recent study. Mrad et al. reported that inhibition of SPHK1-dependent production of S1P by B16 melanoma cells increased the number of M1-polarized macrophages and tumor growth. The latter was, however, mediated by a macrophage-independent mechanism, since tumor growth was accelerated by SPHK1/S1Pdependent production of transforming growth factor (TGF)$\beta$ by melanoma cells themselves (155). Apparently, not only the phenotype transition from inflammatory M1-like to immune-suppressive M2-like macrophages contributes to cancer progression, but also an overshooting inflammatory response mediated by macrophages may provoke cell transformation and tumor growth as shown for colitis-associated colon cancer (CAC). Thereby, SPHK/S1P/S1PR-dependent activation of macrophages and the subsequent production of proinflammatory cytokines were established as important factors in contributing to chronic intestinal inflammation resulting in CAC development. This has been proposed to be in part macrophage dependent, when SPHK1 expression was upregulated as a result of SPHK2 deletion, thereby enhancing S1P levels. In this setting, intracellular S1P activated NF- $\kappa \mathrm{B}$ signaling, which culminated in pro-inflammatory gene transcription of IL-6 and TNF- $\alpha$. Both cytokines triggered a feed-forward amplification loop with TNF- $\alpha$ amplifying NF- $\kappa$ B signaling and IL-6 maintaining persistent S1PR1-dependent STAT3 activation, supporting chronic inflammation and CAC development (124). Another study showed that blocking the SPHK/S1P axis and thus, macrophage activation, attenuates colon cancer. Mechanistically, inhibition of SPHK1 in peritoneal macrophages reduced COX-2 and TNF- $\alpha$ expression, which lowered the formation of aberrant crypt foci in the colons of mice injected with the carcinogen Azoxymethane (156). In terms of S1P-dependent production of pro-inflammatory cytokines by macrophages it apparently needs to be discriminated between the extra- and intracellular actions of S1P during carcinogenesis. As mentioned, extracellular S1P formation produced by apoptotic tumor cells induces the secretion of anti-inflammatory cytokines, while intracellular S1P induces a pro-inflammatory cytokine signature of macrophages in the context of cancer.

Besides affecting cytokine production, the S1P/S1PR axis can induce pro-angiogenic properties of macrophages and therefore contribute to tumor angiogenesis and, consequently, metastasis. Macrophage-specific deletion of S1PR1 in a mammary carcinoma model enhanced lung metastasis by 
inducing tumor lymphangiogenesis. Mechanistically, S1PR1 signaling in lymph vessel-associated macrophages induced NLRP3 expression and IL-1 $\beta$ production, which showed direct pro-lymphangiogenic activity, thereby accelerating tumor progression by promoting metastasis (132). Beside the lymphatics, metastasis also occurs via the bloodstream, which requires tumor angiogenesis. One major driver of tumor angiogenesis is hypoxia, which at the same time affects macrophage biology in inflammation, cancer, or infection. The oxygen-sensitive transcription factors hypoxia inducible factors $1 \alpha$ and $2 \alpha$ (HIF- $1 \alpha$, HIF- $2 \alpha$ ) are the master regulators toward decreased oxygen tension, coordinating many of the multiple hypoxic responses. In tumor cells there is evidence that hypoxia causes a rapid activation of SPHK1, preceding HIF- $1 \alpha$ accumulation (157). Although details remain unknown, ROS appeared to activate SPHK1, while the accumulating S1P, via the Akt/GSK3ß pathway, attenuated HIF-1 $\alpha$ proteasomal degradation. In renal cell carcinoma, SPHK1 activity controlled HIF- $2 \alpha$ expression (158) and the S1PR antagonist FTY720 attenuated both HIF- $1 \alpha$ and HIF- $2 \alpha$ accumulation in several human cancer cell lines (159). S1P released by dying cancer cells also triggered HIF- $1 \alpha$ accumulation in macrophages downstream of S1PR1, even under normoxic conditions (160). In contrast to hypoxic tumor cells, where S1P may be selfsufficient to accumulate HIF- $1 \alpha$ the situation in macrophages seems different. Macrophages sensing S1P from dying cancer cells required a second stimulus, most likely transforming growth factor (TGF)- $\beta$ to stabilize HIF- $1 \alpha$ under normoxia. HIF- $1 \alpha$ expression under these conditions established a pro-angiogenic macrophage phenotype (160), indicating that S1P/S1PR1 signaling may promote tumor angiogenesis in general.

To sum up, studies so far may indicate a critical role of the SPHK/S1P/S1PR axis in macrophage activation and polarization, contributing to cancer development and metastasis. However, more studies are needed to clarify the exact role of the S1P-induced functional consequences for macrophage biology in different tumor entities, especially in respect of utilizing the SPHK/S1P/S1PR axis for cancer therapy. As outlined above, inhibiting one SPHK will provoke over-activation of the remaining SPHK and this may cause severe side effects. Therefore, a cell-type specific or S1PR-specific inhibition of the $\mathrm{S} 1 \mathrm{P} / \mathrm{S} 1 \mathrm{PR}$ axis appears a more rational approach for intervention. Interestingly, in contrast to S1PR1, S1PR2 was reported to limit tumor development and angiogenesis in one study, which involved S1PR2 on myeloid cells (161). Thus, S1PR1 and S1PR2 may show opposing effects on tumor angiogenesis, making S1PR1 a potentially more interesting target when focusing on TAM.

\section{Atherosclerosis}

Macrophages are key cellular mediators of atherosclerosis, as they accumulate in atherosclerotic plaques and the macrophage content and activation state are linked to the progression and the regression of atherosclerosis (162). Macrophages in atherosclerotic plaques are exposed to mediators in the circulation, including S1P. In the circulation S1P is mainly derived from erythrocytes, platelets, or the endothelium. About two-thirds of the circulatory S1P is associated with HDL, followed by its association with albumin and other lipoproteins (163). HDL is known to limit inflammatory responses during atherogenesis. Besides, HDL is also recognized for its general host defense activity, which is linked to its ability to scavenge and limit endotoxin toxicity as well as immune cell modulatory responses, affecting the cholesterol content in plasma membrane lipid rafts (164). HDL functions as a reservoir for several proteins and lipids with immunomodulatory activities, among them S1P. ApoM, a genetic variant of ApoA-1, is mainly associated with HDL and the carrier of S1P in HDL (165). A lipophilic pocket of ApoM not only ligates S1P but also molecules such as oxidized phospholipids or retinol, suggesting some kind of competition (166). ApoM levels are subjected to variations, with drastically reduced amounts during diseases such as atherosclerosis, coronary artery disease, or myocardial infarction as well as acute phase responses. Several studies attributed individual HDL functions as partially or entirely dependent on HDL-bound S1P (167). The mechanism for ApoM-mediated modulation of S1P function may reside in retarding S1P degradation (168) and/or strengthening its agonistic properties by binding HDL via scavenger receptors and thereby bringing S1P in close proximity with S1PRs (169).

The nature of S1P in the pathogenesis of atherosclerosis is ambivalent, although concepts on a defensive role prevail. Toward a protective function, S1P is supposed to promote survival and prevent apoptosis of endothelial cells and macrophages, to induce phosphorylation of endothelialtype NO-synthase (eNOS), which provokes vessel relaxation, to preserve endothelial barrier function by stabilizing cellcell junctions, and to attenuate attachment of blood cells to the endothelium by inhibiting expression of endothelial cell adhesion molecules (170, 171). Harmful properties of S1P are discussed concerning its ability to recruit lymphocytes to sites of inflammation, to act chemotactic and stimulatory for other immune cells, i.e., monocytes/macrophages, to indirectly shape the atheroprotective B1-cell population, or to augment thrombin-induced expression of tissue factor in endothelial cells to foster the coagulation cascade (170, 171). Concerning macrophages, S1PR2 retains them in atherosclerotic plaques and regulates their inflammatory cytokine secretion to promote atherosclerosis (135). Also S1PR3 on monocytes/macrophages contributes to their accumulation in atherosclerotic lesions, thereby adding to a pro-inflammatory, pro-atherogenic environment (172). Hereby S1PR2 and S1PR3 signaling both promote macrophage accumulation in plaques, although by exerting opposing effects on monocyte/macrophage migration. However, other studies see the macrophage-S1P-axis in an atheroprotective context. S1P and its analog FTY720 reduced atherosclerotic lesions, both in the aortic root and brachiocephalic artery, and almost completely blunted necrotic core formation (173). Although a direct connection to macrophages in atherosclerotic plaques was not made, this observation may refer to the modulating role of S1PR signaling in macrophage recruitment, since FTY20 targets S1PR3 but not S1PR2. Alternatively, it may be connected to polarization of macrophages toward an anti-inflammatory, regenerative, healing 
phenotype as discussed above. In line, providing KRP-203, an S1PR1 agonist, to low-density lipoprotein receptor-deficient mice on a cholesterol-rich diet reduced atherosclerotic lesion formation and reduced macrophage pro-inflammatory activation (174). These experiments would argue for S1PR1 in mediating the anti-atherogenic effects of S1P. Besides the ability of S1P to induce alternative macrophage polarization and thereby to attenuate oxidized LDL-induced lipid accumulation, the atheroprotective effect of S1P was also related to its ability to enhance cell survival and to attenuate macrophage pro-apoptotic signaling (175). Mechanistically, HDL-associated S1P attenuated macrophage apoptosis by activating STAT3 and causing survivin expression, presumably via cooperate signaling through $\mathrm{S} 1 \mathrm{PR} 2 / 3$, as recapitulated by pharmacological interventions (75). As many HDL effects are attributed to its S1P load, it is of interest that the physiologically crucial and most relevant role of HDL in reverse cholesterol transport is now also proven to be affected by S1P (176). The transcriptional and functional ABCA1 regulatory pathway, facilitating cholesterol efflux, demanded S1PR3. The authors established LXR to be involved in S1P facilitated cholesterol efflux and identified the critical role of S1PR3.

It is interesting to note that approaches are undertaken to make use of the beneficial HDL-S1P signaling axis for the treatment of diseases. Only HDL, manufactured to incorporate $\mathrm{S} 1 \mathrm{P}$, was cardioprotective in a model of ischemia reperfusion injury (177) and S1P-loaded HDL enhanced eNOS activation in endothelial cells (178). In general, the anti-inflammatory HDL function can be boosted by S1P-loading and exploited by $\mathrm{S} 1 \mathrm{P}$ receptor-targeting to prevent and even turn off ongoing inflammation (179). Another strategy follows the observation that ApoM levels are correlative to biological S1P-signaling. Resveratrol, a proposed supplement to prevent atherosclerosis, is reported to modulate S1P levels by affecting ApoM levels (180). It can be speculated that some of the reported anti-atherosclerotic effects of resveratrol can be explained by increasing plasma levels of ApoM in conjunction with its S1P-association.

Although many details on the role of S1P and macrophages during atherosclerosis still need to be discovered, a gross simplification would favor anti-atherosclerotic actions of S1PR1 and S1PR3, while pro-atherosclerotic functions of S1PR2 may dominate. Mechanistically, the anti-inflammatory impact of S1P toward macrophages, likely transmitted via S1PR1, may add to convey atheroprotective signals. Uncertainties remain, as we are not aware how S1P concentrations, either HDL-bound or associated with other carriers, develop over time with plague progression and how the S1P receptor profile may change in early vs. late stages of the disease. As macrophages are prone to many environmental incoming signals, GPCR activation by S1P may dominate, be modulated, or be overruled. This makes predictions on the macrophage S1P-S1PR signaling axis difficult. However, controlled in vivo experimentation, using genetically modified animals in combination with pharmacological tools that are progressing toward higher selectivity, will help to answer some of the demanding questions in the future.

\section{Fibrosis}

Macrophages are one of the key players during resolution of inflammation as the wound healing response has to be tightly regulated $(181,182)$. Disturbances within any stage of the wound healing process may cause chronicity, while an overshooting healing response can induce fibrosis within different organs such as lung, liver, heart, or kidney. Tissue fibrosis is characterized by increased proliferation and activation of fibroblasts that trigger excessive accumulation of extracellular matrix components eventually initiating organ failure and death (182, 183). Macrophages may serve as critical mediator during fibroblast activation and proliferation by releasing pro-fibrotic mediators such as TGF- $ß$, IL-13, or platelet-derived growth factor (PDGF) (184). There is evidence that the infiltration of antiinflammatory M2 macrophages into fibrotic areas of the lung is a key regulator for the development and progression of idiopathic pulmonary fibrosis (IPF) $(185,186)$.

A role for S1P in IPF progression was already assumed by showing that serum and bronchoalveolar lavage of diseased mice or patients exhibit increased S1P levels and show enhanced SPHK1 protein expression, both correlated with impaired lung function (187, 188). Mechanistically, S1P is implicated in secreting pro-fibrotic factors that cause the excessive activation and proliferation of fibroblasts, thereby advancing tissue fibrosis. Specifically, studies pointed to a role of the SPHK/S1P/S1PR axis in TGF-ß-driven fibrosis induction. This was demonstrated by blocking SPHK1, which in turn reduced TGF- $\beta$ secretion and lung fibrosis in murine models of $\operatorname{IPF}(187,189)$. It has also been shown that the S1P/S1PR axis in macrophages contributes to the production of pro-fibrotic factors and thereby adds to IPF development (190). Along those lines, Zhao et al. used S1PR2 $2^{-/-}$mice and noticed attenuated IPF in animals subjected to bleomycin. In this model S1PR2-expressing alveolar macrophages most likely promote IPF as shown by bone marrow transfer experiments and the enhanced S1PR2dependent production of pro-fibrotic IL-13 that initiates a STAT6-dependent response in macrophages. More mechanistic studies using macrophage-specific $\mathrm{S} 1 \mathrm{PR}^{-/-}$mice will be needed to decipher the exact role of the S1P/S1PR axis in the development and progression of IPF. The SPHK/S1P/S1PR signaling axis also accelerates liver fibrosis by directly activating fibroblast motility and fibrosis-induced angiogenesis $(191,192)$. In a more recent study it became apparent that SPHK1-induced CCL2 secretion from Kupffer cells activated fibroblasts and thereby fostered progression of liver fibrosis (193). The finding that S1P signaling adds to the pathogenesis of tissue fibrosis was already shown in the kidney, when partial nephrectomized rats were treated with FTY720. Blocking the S1P/S1PR axis by FTY720 diminished renal fibrosis, characterized by reduced expression of TNF- $\alpha$, TGF- $\beta$, and the production of extracellular matrix proteins (194). For renal macrophages protection toward fibrosis was linked to SPHK2-dependent S1P signaling. SPHK2deficient kidney-resident macrophages shifted toward the M2 phenotype due to changes in the glycolytic pathway, which reduced renal fibrosis by lowering the production of proinflammatory cytokines such as IL-1 $\beta$ and TNF- $\alpha$ (125). 
Evidently, S1P contributes to macrophage-dependent fibrotic responses by shaping their activation, particularly the release of pro-fibrotic cytokines/chemokines such as TGF-B, IL-13, or CCL2. Addressing the distinct role of S1P in macrophage-driven fibrosis in detail may open the potential to foster mechanisms toward resolution of fibrosis.

\section{I/R Injury}

Ischemia-reperfusion-induced injury ( $\mathrm{I} / \mathrm{R}$ injury) plays a major role during stroke and myocardial infarction, and is accompanied by inflammation that promotes injury. Macrophages play a crucial role in resolving inflammation and promoting repair following ischemic injury (195-197). Targeting S1P receptors has shown promising results in $I / R$ injury models. However, while macrophages are used as readout parameters, their functional involvement largely remains unclear. S1P levels during resolution of focal cerebral ischemia in mice increased (198), when macrophages promote repair. Treating mice in a model of experimental stroke with FTY720 reduced lesion size and improved neurological function, which was accompanied by decreased numbers of activated microglia/macrophages in the ischemic lesion (199). Reduced inflammatory microglia/macrophage infiltration was confirmed in models of focal cerebral ischemia and observed under long-term protective effects of FTY720 (200). Whether reduced infiltration of inflammatory microglia/macrophage were a result of reduced recruitment into the affected area or due to changes in cell activation remains an open question. Intraocular injection of a humanized monoclonal S1P antibody (sonepcizumab) into ischemic retina significantly reduced the macrophage influx in oxygen-induced ischemic retinopathy (201). Attenuated macrophage infiltrates and their proinflammatory cytokine expression were furthermore observed when applying the S1PR1 agonist SEW2871 in mice subjected to hepatic (202) or renal $I / R$ injury (203). Based on the observed lymphopenia in these models, SEW2871 acted as a functional S1PR1 antagonist as expected. However, lymphopenia was not the reason for protection as mice, harboring a selective S1PR1 knockout in proximal tubule cells, were protected as well (204). In some analogy, in a model of cisplatin-induced nephropathy performed in mice with a deletion of S1PR1 in tubule cells reduced kidney damage and a lower level of proinflammatory cytokines and infiltrated macrophage were noticed (205). To conclude, the protective effect of S1PR agonism in the kidney was largely macrophage independent, whereas tissue regeneration following I/R injury required S1PR1/3 signaling and was linked to the release of neutrophil gelatinase-associated lipocalin (LCN2) from macrophages, again underscoring the role of macrophages in tissue regeneration after I/R injury (206). S1PR1/3 activation also protected against cardiac ischemia-reperfusion injury as the accompanying tissue injury in mice was reduced by myonectin, which triggered S1P and protected cardiomyocytes from apoptosis and macrophages from their inflammatory activation. Administration of the S1PR1/3 antagonist VPC23019 reduced the protective potential of myonectin and increased myocardial injury (207). Understanding the role of macrophages in S1P-dependent protection from I/R injury will require further studies by e.g., employing macrophage-specific $\mathrm{S} 1 \mathrm{PR}^{-/-}$mice.

\section{Infection}

Sphingolipids are involved in immunity to infection, with prominent roles being assigned to ceramide and sphingosine (208-210). However, an impact of the SPHK/S1P/S1PR axis under infectious conditions requires further studying. Data from cell culture suggest a role of S1P in pathogen uptake and killing, while information from in vivo models is scarce. SPHK1 was required to form lung granuloma and prevented brain infection with a particular $C$. neoformans strain that is restricted to intracellular replication in macrophages (108). Logically, SPHK1-deficient showed a higher susceptibility to C. neoformans infection (108). SPHK1 was also required for the protective principle of glucocorticoids in a model of acute lung injury, triggered by LPS and oleic acid. Downstream of the glucocorticoid receptor SPHK1 was upregulated in macrophages, provoking a systemic S1P increases and reducing inflammatory cell infiltrates (211). Enhanced SPHK1 expression was also observed in macrophages in inflamed murine and human lungs in pneumonia, while genetic SPHK1 deletion protected mice from pneumonia-induced hyperpermeability. Unfortunately, the role of macrophage-specific SPHK1 in this process remained unclear (212). SPHK2-deficient mice showed a higher susceptibility to Streptococcus pneumonia induced lung inflammation, although there was no change in neutrophil function, leaving room for a role of macrophages (213).

With regard to S1P receptors, deletion of S1PR2 was protective in models of bacterial sepsis. S1PR2 promoted macrophage pyroptosis, which is linked to a cytokine storm, upon E. coli infection, while a S1PR2 knockout improved survival (76). Survival of S1PR2 knockout mice was also seen during cecal ligation and puncture or intratracheal administration E. coli, which was linked to an enhanced phagocytic function of S1PR2deficient macrophages (98). S1PR3 supports ROS generation in macrophages, thereby aiding in killing bacteria and promoting phagosome maturation upon cecal ligation and puncture, where S1PR3 knockout showed increased lethality (104). Septic patients with monocytes showing enhanced S1PR3 expression cleared bacteria more efficiently, which was linked to a preferable outcome (104). Accordingly, the S1PR agonist FTY720 prevented clearance of bacteria albeit increasing colonic inflammation and neutrophil infiltration in a model of gastrointestinal infection with the mouse enteric pathogen Citrobacter rodentium. FTY720 targets all S1P receptors, with the exception of S1PR2, showing short term agonistic activity, followed by receptor desensitization due to their degradation. Thereby FTY720 traps lymphocytes in secondary lymphatic organs by disabling them to follow the S1P gradient toward the circulation. FTY720 treated animals therefore exhibit peripheral blood lymphopenia with significantly lower numbers of colonic dendritic cells, macrophages, and $\mathrm{T}$ cells. Infected mice treated with FTY720 revealed an impaired innate immune response and reduced type 1 adaptive immunity (214). Therefore, targeting S1PRs with rather non-specific tools will likely not be beneficial during infection. However, it might be worth considering to selectively targeting S1PR2 as it likely 


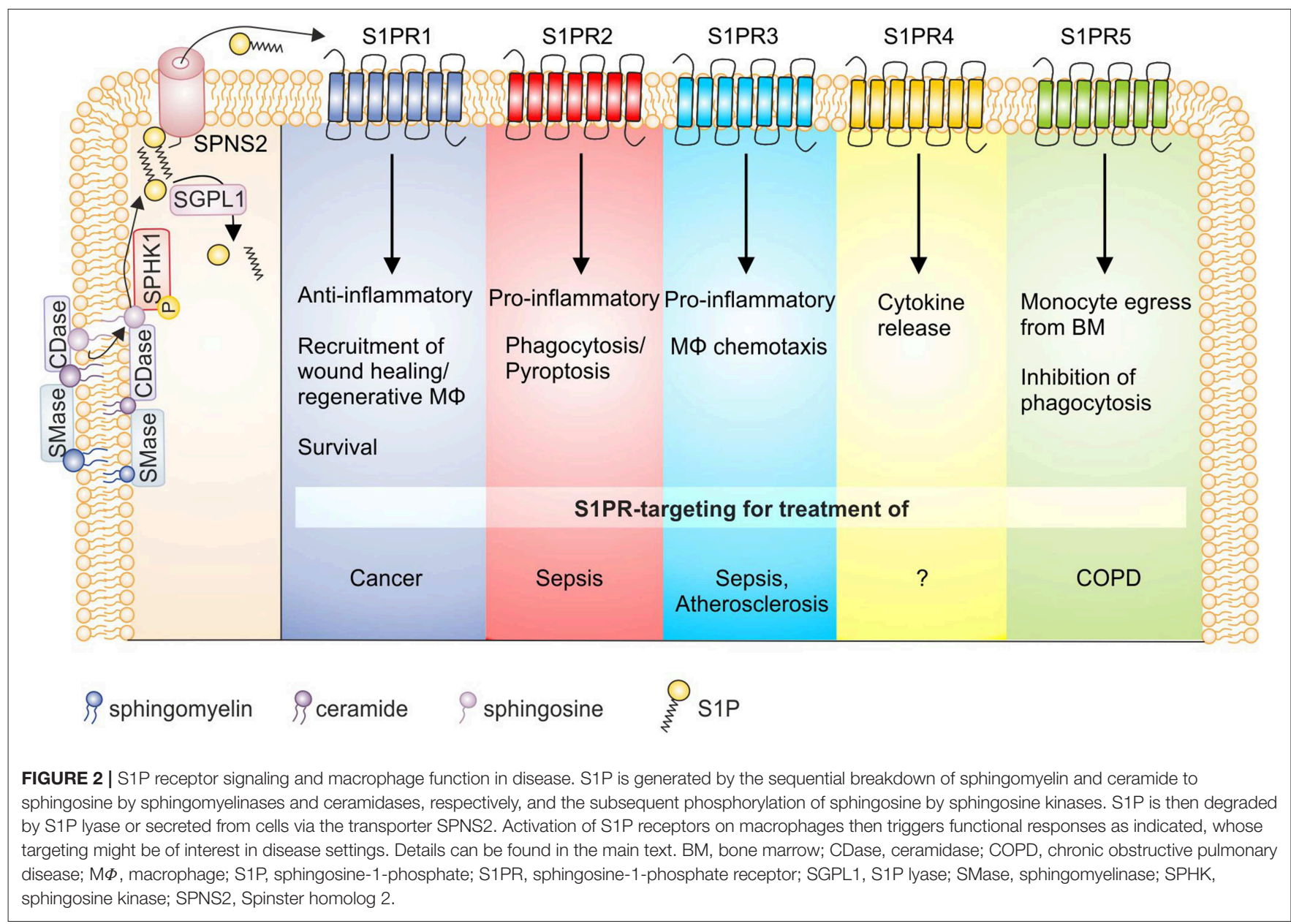

increases the anti-microbial macrophage function and enhances macrophage survival. Moreover, S1PR2 antagonism will probably not induce immune paralysis, since S1PR1 is the important receptor promoting lymphocyte recruitment to the circulation.

\section{CONCLUSIONS}

Macrophages are key players in maintaining tissue homeostasis, which requires a remarkable repertoire to sense microenvironmental cues that signal disturbed homeostasis. S1P is a good example of a sensing/signaling molecule, since its tissue levels, except for blood and lymph, are constitutively low. Rising S1P levels therefore imply an altered microenvironment, which is sensed by macrophages and their progenitors. This provokes monocyte/macrophage trafficking, survival, and altered effector functions. These changes are involved in a number of diseases as highlighted in this review (Figure 2). The source of S1P and the receptor profile are critical determinants of the S1P impact on macrophages. Intracellular S1P produced by SPHK1 mostly promotes inflammatory macrophage activation and increases anti-microbial properties including phagosome maturation.

S1P signaling through individual S1PRs has pleiotropic and sometimes even divergent effects. In monocytes/macrophages
S1PR1 recruits wound healing and/or regenerative macrophages (215), acts as a survival signal (88) and predominantly causes anti-inflammatory macrophage polarization (137). In IL-4 stimulated macrophages S1PR1 expression is enhanced (81), while in pro-inflammatory activated phagocytes S1PR1 and S1PR4 appeared downregulated, at least at mRNA level (82). Moreover, S1PR1 stimulated EPO-signaling in macrophages to enhance apoptotic cell clearance through $\operatorname{PPAR} \gamma$, which adds to the anti-inflammatory/regenerative macrophage phenotype (90). However, when S1PR1 is activated in the context of endogenous SPHK1 activation in macrophages, pro-inflammatory effects may prevail (124). Therefore, targeting S1PR1 affects inflammatory macrophage activation needs to be approached in a context-dependent manner, although it emerges as a promising target in cancer. S1PR2 generally seems to oppose S1PR1 signals. The receptor regulates macrophage retention in atherosclerotic plaques and provokes cytokine secretion to promote inflammation (135). However, more recent data proposed a S1PR2- $\mathrm{G}_{12 / 13}$ signaling axis in macrophages that augmented protective B-cell populations to ameliorate atherosclerosis (216). This receptor also enhanced Fc $\gamma$ receptorfacilitated phagocytosis in response to antibody opsonized particles, but not complement-mediated phagocytosis (97). 
It was also proposed that S1PR2 impaired phagocytosis and antimicrobial defense in the pathogenesis of sepsis (98). Furthermore, S1PR2 deficiency/S1PR2 inhibition decreased macrophage pyroptosis and improved survival in E. coli sepsis, posing this receptor as a promising therapeutic approach during sepsis (76). These observations support the notion of S1PR2 in contributing toward proinflammatory macrophage polarization (128), although it may play a role in inflammation resolution by increasing cAMP levels as well (144). S1PR3 mediates chemotaxis of macrophages, in vitro, and provokes migration of cells to plaques in atherosclerotic mice (172) and recruits macrophages in bile duct-ligated mice to promote hepatic inflammation and fibrosis (85). In general, S1PR3 appears to mediate pro-inflammatory responses. This is coupled to antimicrobial function as S1PR3 expression was elevated in septic patients, linked to bacterial clearance and a better outcome (104). Mechanistically, bacterial killing in macrophages was fostered by enhanced ROS formation and phagosome maturation. Activating S1PR3 on macrophages therefore might be beneficial to promote antimicrobial immunity. S1PR4 is less well studied than S1PR1 to S1PR3, but is abundant on immune cells, among them macrophages (217). S1PR4 was required to produce the Th17 polarizing cytokine IL- 6 by dendritic cells (218). This may also be true for macrophages since activation of this receptor on TAM by S1P, released from apoptotic cells, caused formation of tumor promoting cytokines, including IL-6 and IL-10 (147). Under pro-inflammatory conditions macrophages downregulate S1PR4 (82), which has also been shown for plasmacytoid dendritic cells (219). Whether S1PR4 downregulation is required for pro-inflammatory signaling to take place will require further studying. There is evidence that S1PR5 is involved in the egress of patrolling monocytes from the bone marrow (220), thereby potentially contributing to the tissue macrophage pool during inflammation. As S1P did not function as a chemoattractant for these cells nor did it affect their viability in vitro, detailed mechanisms remained unexplored. Alveolar macrophages from patients with COPD are defective in their ability to phagocytose apoptotic cells. As a significant association was noted between S1PR5 expression and both lung function as well as defective phagocytosis it is concluded that this receptor might be a potential therapeutic target in COPD (93).

Besides evidence suggesting a role of S1P/S1PR signaling in shaping macrophage-specific tissue homeostasis, a number of questions still need to be addressed. The role of S1P in emerging areas such as macrophage immune metabolism and innate memory formation may require our attention. This is supported by findings that SPHK2 deficiency reduces glycolysis in macrophages (125), and produces intracellular S1P as a cofactor for HDACs to modulate epigenetics (221), both of which are hallmarks of trained macrophage immunity (222).

\section{REFERENCES}

1. Kaufmann SH. Immunology's foundation: the 100-year anniversary of the Nobel Prize to Paul Ehrlich and Elie Metchnikoff. Nat Immunol. (2008) 9:705-12. doi: 10.1038/ni0708-705
Moreover, experiments using specific deletion of individual components of this signaling axis, particularly individual S1PRs in macrophages will allow identifying potential pharmaceutical targets to be exploited for disease conditions mentioned above. This is of special importance given the sometimes antithetic properties of signaling through individual S1PRs. Targeting the SphK/S1P/S1PR axis is already the object of a number of clinical trials. Most notably S1PR1 modulators (Fingolimod, MT-1303, Ozanimod) are tested or already in clinical use for treating inflammation-driven diseases such as multiple sclerosis, inflammatory bowel disease and psoriasis (223). These drugs are thought to act mainly through the induction of sustained lymphopenia by trapping $\mathrm{T}$ cells in lymphatic organs. Thereby, S1PR1 modulators dampen the inflammatory response and thus reduce disease severity. It is unclear how these drugs affect macrophage biology in patients. Targeting macrophage S1PR1 in cancer may be of interest, as outlined above. However, in the case of cancer therapy, as well as during infection, sustained lymphopenia triggered by S1PR1 antagonism may rather be disadvantageous, since $\mathrm{T}$ cells are needed at the tumor site for a proper anti-tumor response (224). Targeting S1P levels globally using the anti-S1P monoclonal antibody Sonepcizumab failed in a phase II study of metastatic renal cell carcinoma (225). A phase I clinical trial with Safingol, which inhibits SphK besides other kinases, published in 2011 showed potential in treating solid tumors when combined with chemotherapy (226). Administration of Safingol alone was ineffective and further clinical were so far not conducted. The SPHK2 inhibitor ABC294640 showed promise in a phase I trial in patients with advanced solid tumors (227). However, given the opposing effects of signaling through individual S1PRs, targeting individual S1PRs may be more rational to unleash the full potential of S1P modulators. In the context of cancer and with a focus on immunity, S1PR4 may represent an interesting drug target since it is mainly expressed on immune cells including macrophages and $\mathrm{T}$ cells, and does not affect $\mathrm{T}$ cell trafficking similar to S1PR1.

\section{AUTHOR CONTRIBUTIONS}

All authors listed have made a substantial, direct and intellectual contribution to the work, and approved it for publication.

\section{ACKNOWLEDGMENTS}

We apologize to researchers whose primary observations were cited indirectly by referring to current reviews. Our work was supported by Deutsche Krebshilfe (70112451), Deutsche Forschungsgemeinschaft (SFB 1039, TP B04 and TP B06, FOR 2438 P8, GRK 2336, TP1 and TP6), and Sander Foundation.

2. Lavin Y, Merad M. Macrophages: gatekeepers of tissue integrity. Cancer Immunol Res. (2013) 1:201-9. doi: 10.1158/2326-6066.CIR-13-0117

3. Wynn TA, Chawla A, Pollard JW. Macrophage biology in development, homeostasis and disease. Nature. (2013) 496:445-55. doi: $10.1038 /$ nature 12034 
4. Hulsmans M, Clauss S, Xiao L, Aguirre AD, King KR, Hanley A, et al. Macrophages facilitate electrical conduction in the heart. Cell. (2017) 169:510-22.e20. doi: 10.1016/j.cell.2017.03.050

5. Wolf Y, Boura-Halfon S, Cortese N, Haimon Z, Sar Shalom H, Kuperman $\mathrm{Y}$, et al. Brown-adipose-tissue macrophages control tissue innervation and homeostatic energy expenditure. Nat Immunol. (2017) 18:665-74. doi: $10.1038 /$ ni.3746

6. Pollard JW. Trophic macrophages in development and disease. Nat Rev Immunol. (2009) 9:259-70. doi: 10.1038/nri2528

7. Corliss BA, Azimi MS, Munson JM, Peirce SM, Murfee WL. Macrophages: an inflammatory link between angiogenesis and lymphangiogenesis. Microcirculation. (2016) 23:95-121. doi: 10.1111/micc.12259

8. Minutti CM, Modak RV, Macdonald F, Li F, Smyth DJ, Dorward DA, et al. A macrophage-pericyte axis directs tissue restoration via amphiregulininduced transforming growth factor beta activation. Immunity. (2019) 50:645-54 e6. doi: 10.1016/j.immuni.2019.01.008

9. Hu MS, Walmsley GG, Barnes LA, Weiskopf K, Rennert RC, Duscher D, et al. Delivery of monocyte lineage cells in a biomimetic scaffold enhances tissue repair. JCI Insight. (2017) 2:96260. doi: 10.1172/jci.insight.96260

10. Minutti CM, Knipper JA, Allen JE, Zaiss DM. Tissue-specific contribution of macrophages to wound healing. Semin Cell Dev Biol. (2017) 61:3-11. doi: 10.1016/j.semcdb.2016.08.006

11. Guilliams M, Scott CL. Does niche competition determine the origin of tissue-resident macrophages? Nat Rev Immunol. (2017) 17:451-60. doi: $10.1038 /$ nri.2017.42

12. Bain CC, Hawley CA, Garner H, Scott CL, Schridde A, Steers NJ, et al. Long-lived self-renewing bone marrow-derived macrophages displace embryo-derived cells to inhabit adult serous cavities. Nat Commun. (2016) 7:ncomms11852. doi: 10.1038/ncomms 11852

13. Mass E, Ballesteros I, Farlik M, Halbritter F, Gunther P, Crozet L, et al. Specification of tissue-resident macrophages during organogenesis. Science. (2016) 353:aaf4238. doi: 10.1126/science.aaf4238

14. Ginhoux F, Jung S. Monocytes and macrophages: developmental pathways and tissue homeostasis. Nat Rev Immunol. (2014) 14:392-404. doi: $10.1038 /$ nri3671

15. Brune B, Courtial N, Dehne N, Syed SN, Weigert A. Macrophage NOS2 in Tumor Leukocytes. Antioxid Redox Signal. (2017) 26:1023-43. doi: 10.1089/ars.2016.6811

16. Hoeffel G, Chen J, Lavin Y, Low D, Almeida FF, See P, et al. C$\mathrm{Myb}(+)$ erythro-myeloid progenitor-derived fetal monocytes give rise to adult tissue-resident macrophages. Immunity. (2015) 42:665-78. doi: 10.1016/j.immuni.2015.03.011

17. Perdiguero EG, Klapproth K, Schulz C, Busch K, Azzoni E, Crozet L, et al. Tissue-resident macrophages originate from yolk-sac-derived erythromyeloid progenitors. Nature. (2014) 518:547-51. doi: 10.1038/nature13989

18. McGovern N, Schlitzer A, Gunawan M, Jardine L, Shin A, Poyner E, et al. Human dermal $\mathrm{CD}^{+} 4^{+}$cells are a transient population of monocyte-derived macrophages. Immunity. (2014) 41:465-77. doi: 10.1016/j.immuni.2014.08.006

19. Bain CC, Mowat AM. Macrophages in intestinal homeostasis and inflammation. Immunol Rev. (2014) 260:102-17. doi: 10.1111/imr.12192

20. Epelman S, Lavine KJ, Randolph GJ. Origin and functions of tissue macrophages. Immunity. (2014) 41:21-35. doi: 10.1016/j.immuni.2014.06.013

21. van de Laar L, Saelens W, De Prijck S, Martens L, Scott CL, Van Isterdael G, et al. Yolk sac macrophages, fetal liver, and adult monocytes can colonize an empty niche and develop into functional tissue-resident macrophages. Immunity. (2016) 44:755-68. doi: 10.1016/j.immuni.2016.02.017

22. Roberts AW, Lee BL, Deguine J, John S, Shlomchik MJ, Barton GM. Tissue-resident macrophages are locally programmed for silent clearance of apoptotic cells. Immunity. (2017) 47:913-27 e6. doi: 10.1016/j.immuni.2017.10.006

23. Sierro F, Evrard M, Rizzetto S, Melino M, Mitchell AJ, Florido M, et al. A liver capsular network of monocyte-derived macrophages restricts hepatic dissemination of intraperitoneal bacteria by neutrophil recruitment. Immunity. (2017) 47:374-88 e6. doi: 10.1016/j.immuni.2017.07.018

24. Bajpai G, Schneider C, Wong N, Bredemeyer A, Hulsmans M, Nahrendorf $\mathrm{M}$, et al. The human heart contains distinct macrophage subsets with divergent origins and functions. Nat Med. (2018) 24:1234-45 doi: 10.1038/s41591-018-0059-x

25. Chakarov S, Lim HY, Tan L, Lim SY, See P, Lum J, et al. Two distinct interstitial macrophage populations coexist across tissues in specific subtissular niches. Science. (2019) 363:eaau0964. doi: 10.1126/science.aau0964

26. Heinz S, Benner C, Spann N, Bertolino E, Lin YC, Laslo P, et al. Simple combinations of lineage-determining transcription factors prime cisregulatory elements required for macrophage and B cell identities. Mol Cell. (2010) 38:576-89. doi: 10.1016/j.molcel.2010.05.004

27. Jenkins SJ, Hume DA. Homeostasis in the mononuclear phagocyte system. Trends Immunol. (2014) 35:358-67. doi: 10.1016/j.it.2014.06.006

28. Scott CL, T'Jonck W, Martens L, Todorov H, Sichien D, Soen B, et al. The transcription factor ZEB2 is required to maintain the tissue-specific identities of macrophages. Immunity. (2018) 49:312-25. doi: 10.1016/j.immuni.2018.07.004

29. Haldar M, Kohyama M, So AY, Kc W, Wu X, Briseno CG, et al. Heme-mediated SPI-C induction promotes monocyte differentiation into iron-recycling macrophages. Cell. (2014) 156:1223-34. doi: 10.1016/j.cell.2014.01.069

30. Okabe Y, Medzhitov R. Tissue-specific signals control reversible program of localization and functional polarization of macrophages. Cell. (2014) 157:832-44. doi: 10.1016/j.cell.2014.04.016

31. Rosas M, Davies LC, Giles PJ, Liao CT, Kharfan B, Stone TC, et al. The transcription factor Gata6 links tissue macrophage phenotype and proliferative renewal. Science. (2014) 344:645-8. doi: $10.1126 /$ science. 1251414

32. Schneider C, Nobs SP, Kurrer M, Rehrauer H, Thiele C, Kopf M. Induction of the nuclear receptor PPAR-gamma by the cytokine GM-CSF is critical for the differentiation of fetal monocytes into alveolar macrophages. Nat Immunol. (2014) 15:1026-37. doi: 10.1038/ni.3005

33. Butovsky O, Jedrychowski MP, Moore CS, Cialic R, Lanser AJ, Gabriely $\mathrm{G}$, et al. Identification of a unique TGF-beta-dependent molecular and functional signature in microglia. Nat Neurosci. (2014) 17:131-43. doi: 10.1038/nn.3599

34. Gosselin D, Link VM, Romanoski CE, Fonseca GJ, Eichenfield DZ, Spann NJ, et al. Environment drives selection and function of enhancers controlling tissue-specific macrophage identities. Cell. (2014) 159:1327-40. doi: 10.1016/j.cell.2014.11.023

35. Kurotaki D, Sasaki H, Tamura T. Transcriptional control of monocyte and macrophage development. Int Immunol. (2017) 29:97-107. doi: 10.1093/intimm/dxx016

36. Murray PJ, Allen JE, Biswas SK, Fisher EA, Gilroy DW, Goerdt S, et al. Macrophage activation and polarization: nomenclature and experimental guidelines. Immunity. (2014) 41:14-20. doi: 10.1016/j.immuni.2014.07.009

37. Murray PJ, Wynn TA. Protective and pathogenic functions of macrophage subsets. Nat Rev Immunol. (2011) 11:723-37. doi: 10.1038/nri3073

38. Stefater JA III, Ren S, Lang RA, Duffield JS. Metchnikoff's policemen: macrophages in development, homeostasis and regeneration. Trends $\mathrm{Mol}$ Med. (2011) 17:743-52. doi: 10.1016/j.molmed.2011.07.009

39. Brune B, Dehne N, Grossmann N, Jung M, Namgaladze D, Schmid T, et al. Redox control of inflammation in macrophages. Antioxid Redox Signal. (2013) 19:595-637. doi: 10.1089/ars.2012.4785

40. Mosser DM, Edwards JP. Exploring the full spectrum of macrophage activation. Nat Rev Immunol. (2008) 8:958-69. doi: 10.1038/nri2448

41. Nahrendorf M, Swirski FK. Abandoning M1/M2 for a network model of macrophage function. Circ Res. (2016) 119:414-7. doi: 10.1161/CIRCRESAHA.116.309194

42. Mantovani A, Sica A, Sozzani S, Allavena P, Vecchi A, Locati M. The chemokine system in diverse forms of macrophage activation and polarization. Trends Immunol. (2004) 25:677-86. doi: 10.1016/j.it.2004.09.015

43. Krausgruber T, Blazek K, Smallie T, Alzabin S, Lockstone H, Sahgal N, et al. IRF5 promotes inflammatory macrophage polarization and TH1-TH17 responses. Nat Immunol. (2011) 12:231-8. doi: 10.1038/ni.1990

44. Hu S, Liu H, Ha Y, Luo X, Motamedi M, Gupta MP, et al. Posttranslational modification of Sirt6 activity by peroxynitrite. Free Radic Biol Med. (2015) 79:176-85. doi: 10.1016/j.freeradbiomed.2014.11.011 
45. Lawrence T, Natoli G. Transcriptional regulation of macrophage polarization: enabling diversity with identity. Nat Rev Immunol. (2011) 11:750-61. doi: 10.1038/nri3088

46. Martinez FO, Helming L, Milde R, Varin A, Melgert BN, Draijer C, et al. Genetic programs expressed in resting and IL-4 alternatively activated mouse and human macrophages: similarities and differences. Blood. (2013) 121:e5769. doi: 10.1182/blood-2012-06-436212

47. Piccolo V, Curina A, Genua M, Ghisletti S, Simonatto M, Sabo A, et al. Opposing macrophage polarization programs show extensive epigenomic and transcriptional cross-talk. Nat Immunol. (2017) 18:530-40. doi: $10.1038 /$ ni. 3710

48. Czimmerer Z, Daniel B, Horvath A, Ruckerl D, Nagy G, Kiss M, et al. The transcription factor STAT6 mediates direct repression of inflammatory enhancers and limits activation of alternatively polarized macrophages. Immunity. (2018) 48:75-90 e6. doi: 10.1016/j.immuni.2017.12.010

49. Kang K, Park SH, Chen J, Qiao Y, Giannopoulou E, Berg K, et al. Interferon-gamma represses M2 gene expression in human macrophages by disassembling enhancers bound by the transcription factor MAF. Immunity. (2017) 47:235-50 e4. doi: 10.1016/j.immuni.2017.07.017

50. Cassetta L, Cassol E, Poli G. Macrophage polarization in health and disease. Sci World J. (2011) 11:2391-402. doi: 10.1100/2011/213962

51. Stout RD, Jiang C, Matta B, Tietzel I, Watkins SK, Suttles J. Macrophages sequentially change their functional phenotype in response to changes in microenvironmental influences. J Immunol. (2005) 175:342-9. doi: 10.4049/jimmunol.175.1.342

52. Strub GM, Maceyka M, Hait NC, Milstien S, Spiegel S. Extracellular and intracellular actions of sphingosine-1-phosphate. Adv Exp Med Biol. (2010) 688:141-55. doi: 10.1007/978-1-4419-6741-1_10

53. Mendelson K, Evans T, Hla T. Sphingosine 1-phosphate signalling. Development. (2014) 141:5-9. doi: 10.1242/dev.094805

54. Pyne S, Adams DR, Pyne NJ. Sphingosine 1-phosphate and sphingosine kinases in health and disease: recent advances. Prog Lipid Res. (2016) 62:93106. doi: 10.1016/j.plipres.2016.03.001

55. Pitman MR, Costabile M, Pitson SM. Recent advances in the development of sphingosine kinase inhibitors. Cell Signal. (2016) 28:1349-63. doi: 10.1016/j.cellsig.2016.06.007

56. Maceyka M, Harikumar KB, Milstien S, Spiegel S. Sphingosine-1-phosphate signaling and its role in disease. Trends Cell Biol. (2012) 22:50-60. doi: 10.1016/j.tcb.2011.09.003

57. Weigert A, Weichand B, Brune B. S1P regulation of macrophage functions in the context of cancer. Anticancer Agents Med Chem. (2011) 11:818-29. doi: 10.2174/187152011797655096

58. Weigert A, Weis N, Brune B. Regulation of macrophage function by sphingosine-1-phosphate. Immunobiology. (2009) 214:748-60. doi: 10.1016/j.imbio.2009.06.003

59. Hannun YA, Obeid LM. Principles of bioactive lipid signalling: lessons from sphingolipids. Nat Rev Mol Cell Biol. (2008) 9:139-50. doi: 10.1038/nrm2329

60. Merrill AH Jr, Stokes TH, Momin A, Park H, Portz BJ, Kelly S, et al. Sphingolipidomics: a valuable tool for understanding the roles of sphingolipids in biology and disease. J Lipid Res. (2009) 50(Suppl):S97-102. doi: 10.1194/jlr.R800073-JLR200

61. Adams DR, Pyne S, Pyne NJ. Sphingosine kinases: emerging structure-function insights. Trends Biochem Sci. (2016) 41:395-409. doi: 10.1016/j.tibs.2016.02.007

62. Takabe K, Kim RH, Allegood JC, Mitra P, Ramachandran S, Nagahashi $\mathrm{M}$, et al. Estradiol induces export of sphingosine 1-phosphate from breast cancer cells via ABCC1 and ABCG2. J Biol Chem. (2010) 285:10477-86. doi: 10.1074/jbc.M109.064162

63. Kawahara A, Nishi T, Hisano Y, Fukui H, Yamaguchi A, Mochizuki N. The sphingolipid transporter spns2 functions in migration of zebrafish myocardial precursors. Science. (2009) 323:524-7. doi: 10.1126/science.1167449

64. Rivera J, Proia RL, Olivera A. The alliance of sphingosine-1-phosphate and its receptors in immunity. Nat Rev Immunol. (2008) 8:753-63. doi: $10.1038 /$ nri2400

65. Kunkel GT, Maceyka M, Milstien S, Spiegel S. Targeting the sphingosine-1phosphate axis in cancer, inflammation and beyond. Nat Rev Drug Discov. (2013) 12:688-702. doi: 10.1038/nrd4099
66. Hla T, Dannenberg AJ. Sphingolipid signaling in metabolic disorders. Cell Metab. (2012) 16:420-34. doi: 10.1016/j.cmet.2012.06.017

67. Bryan AM, Del Poeta M. Sphingosine-1-phosphate receptors and innate immunity. Cell. Microbiol. (2018) 20:e12836. doi: 10.1111/cmi.12836

68. Blaho VA, Hla T. An update on the biology of sphingosine 1-phosphate receptors. J Lipid Res. (2014) 55:1596-608. doi: 10.1194/jlr.R046300

69. Aoki M, Aoki H, Ramanathan R, Hait NC, Takabe K. Sphingosine1-phosphate signaling in immune cells and inflammation: roles and therapeutic potential. Mediat Inflamm. (2016) 2016:8606878. doi: $10.1155 / 2016 / 8606878$

70. Kono M, Mi Y, Liu Y, Sasaki T, Allende ML, Wu YP, et al. The sphingosine1-phosphate receptors S1P1, S1P2, and S1P3 function coordinately during embryonic angiogenesis. J Biol Chem. (2004) 279:29367-73. doi: 10.1074/jbc.M403937200

71. Mendelson K, Zygmunt T, Torres-Vazquez J, Evans T, Hla T. Sphingosine 1-phosphate receptor signaling regulates proper embryonic vascular patterning. J Biol Chem. (2013) 288:2143-56. doi: 10.1074/jbc.M112.427344

72. Hla T, Venkataraman K, Michaud J. The vascular S1P gradient-cellular sources and biological significance. Biochim Biophys Acta. (2008) 1781:47782. doi: 10.1016/j.bbalip.2008.07.003

73. Weis N, Weigert A, von Knethen A, Brune B. Heme oxygenase-1 contributes to an alternative macrophage activation profile induced by apoptotic cell supernatants. Mol Biol Cell. (2009) 20:1280-8. doi: 10.1091/mbc.e08-10-1005

74. Gomez-Munoz A, Kong J, Salh B, Steinbrecher UP. Sphingosine1-phosphate inhibits acid sphingomyelinase and blocks apoptosis in macrophages. FEBS Lett. (2003) 539:56-60. doi: 10.1016/S0014-5793(03)00197-2

75. Feuerborn R, Becker S, Poti F, Nagel P, Brodde M, Schmidt H, et al. High density lipoprotein (HDL)-associated sphingosine 1phosphate (S1P) inhibits macrophage apoptosis by stimulating STAT3 activity and survivin expression. Atherosclerosis. (2017) 257:29-37. doi: 10.1016/j.atherosclerosis.2016.12.009

76. Song F, Hou J, Chen Z, Cheng B, Lei R, Cui P, et al. Sphingosine-1-phosphate Receptor 2 signaling promotes caspase-11-dependent macrophage pyroptosis and worsens Escherichia coli sepsis outcome. Anesthesiology. (2018) 129:311-20. doi: 10.1097/ALN.0000000000002196

77. Monick MM, Mallampalli RK, Bradford M, McCoy D, Gross TJ, Flaherty DM, et al. Cooperative prosurvival activity by ERK and Akt in human alveolar macrophages is dependent on high levels of acid ceramidase activity. J Immunol. (2004) 173:123-35. doi: 10.4049/jimmunol.173.1.123

78. Gude DR, Alvarez SE, Paugh SW, Mitra P, Yu J, Griffiths R, et al. Apoptosis induces expression of sphingosine kinase 1 to release sphingosine1-phosphate as a "come-and-get-me" signal. FASEB J. (2008) 22:2629-38. doi: 10.1096/fj.08-107169

79. Al-Jarallah A, Chen X, Gonzalez L, Trigatti BL. High density lipoprotein stimulated migration of macrophages depends on the scavenger receptor class B, type I, PDZK1 and Akt1 and is blocked by sphingosine 1 phosphate receptor antagonists. PLOS ONE. (2014) 9:e106487. doi: 10.1371/journal.pone.0106487

80. Liao CY, Song MJ, Gao Y, Mauer AS, Revzin A, Malhi H. Hepatocyte-derived lipotoxic extracellular vesicle sphingosine 1-phosphate induces macrophage chemotaxis. Front Immunol. (2018) 9:2980. doi: 10.3389/fimmu.2018.02980

81. Weichand B, Weis N, Weigert A, Grossmann N, Levkau B, Bruene B. Apoptotic cells enhance sphingosine-1-phosphate receptor 1 dependent macrophage migration. Eur J Immunol. (2013) 43:3306-13. doi: 10.1002/eji.201343441

82. Muller J, von Bernstorff W, Heidecke CD, Schulze T. Differential S1P receptor profiles on M1- and M2-polarized macrophages affect macrophage cytokine production and migration. Biomed Res Int. (2017) 2017:7584621. doi: 10.1155/2017/7584621

83. Michaud J, Im DS, Hla T. Inhibitory role of sphingosine 1-phosphate receptor 2 in macrophage recruitment during inflammation. J Immunol. (2010) 184:1475-83. doi: 10.4049/jimmunol. 0901586

84. Ishii M, Kikuta J, Shimazu Y, Meier-Schellersheim M, Germain RN. Chemorepulsion by blood S1P regulates osteoclast precursor mobilization and bone remodeling in vivo. J Exp Med. 207:2793-8. doi: $10.1084 /$ jem. 20101474 
85. Yang L, Han Z, Tian L, Mai P, Zhang Y, Wang L, et al. Sphingosine 1-phosphate receptor 2 and 3 mediate bone marrow-derived monocyte/macrophage motility in cholestatic liver injury in mice. Sci Rep. (2015) 5:13423. doi: 10.1038/srep13423

86. Rathinasamy A, Czeloth N, Pabst O, Forster R, Bernhardt G. The origin and maturity of dendritic cells determine the pattern of sphingosine 1-phosphate receptors expressed and required for efficient migration. J Immunol. (2010) 185:4072-81. doi: 10.4049/jimmunol.1000568

87. Gordon S. Phagocytosis: an immunobiologic process. Immunity. (2016) 44:463-75. doi: 10.1016/j.immuni.2016.02.026

88. Weigert A, Johann AM, von Knethen A, Schmidt H, Geisslinger G, Brune B. Apoptotic cells promote macrophage survival by releasing the antiapoptotic mediator sphingosine-1-phosphate. Blood. (2006) 108:163542. doi: 10.1182/blood-2006-04-014852

89. Arifuzzaman M, Ang WXG, Choi HW, Nilles ML, St. John AL, Abraham SN. Necroptosis of infiltrated macrophages drives Yersinia pestis dispersal within buboes. JCI Insight. (2018) 3:122188. doi: 10.1172/jci.insight.122188

90. Luo B, Gan W, Liu Z, Shen Z, Wang J, Shi R, et al. Erythropoeitin signaling in macrophages promotes dying cell clearance and immune tolerance. Immunity. (2016) 44:287-302. doi: 10.1016/j.immuni.2016.01.002

91. Tran HB, Barnawi J, Ween M, Hamon R, Roscioli E, Hodge G, et al. Cigarette smoke inhibits efferocytosis via deregulation of sphingosine kinase signaling: reversal with exogenous S1P and the S1P analogue FTY720. J Leukoc Biol. (2016) 100:195-202. doi: 10.1189/jlb.3A1015-471R

92. Tran HB, Jersmann H, Truong TT, Hamon R, Roscioli E, Ween $\mathrm{M}$, et al. Disrupted epithelial/macrophage crosstalk via Spinster homologue 2-mediated S1P signaling may drive defective macrophage phagocytic function in COPD. PLoS ONE. (2017) 12:e0179577. doi: 10.1371/journal.pone.0179577

93. Barnawi J, Tran H, Jersmann H, Pitson S, Roscioli E, Hodge G, et al. Potential Link between the Sphingosine-1-Phosphate (S1P) system and defective alveolar macrophage phagocytic function in Chronic Obstructive Pulmonary Disease (COPD). PLoS ONE. (2015) 10:e0122771. doi: 10.1371/journal.pone.0122771

94. Barnawi J, Jersmann H, Haberberger R, Hodge S, Meech R. Reduced DNA methylation of sphingosine-1 phosphate receptor 5 in alveolar macrophages in COPD: a potential link to failed efferocytosis. Respirology. (2017) 22:31521. doi: 10.1111/resp.12949

95. Barnawi J, Tran HB, Roscioli E, Hodge G, Jersmann H, Haberberger R, et al. Pro-phagocytic effects of thymoquinone on cigarette smoke-exposed macrophages occur by modulation of the sphingosine-1-phosphate signalling system. COPD. (2016) 13:653-61. doi: 10.3109/15412555.2016.1153614

96. Duong CQ, Bared SM, Abu-Khader A, Buechler C, Schmitz A, Schmitz G. Expression of the lysophospholipid receptor family and investigation of lysophospholipid-mediated responses in human macrophages. Biochim Biophys Acta. (2004) 1682:112-9. doi: 10.1016/j.bbalip.2004.03.002

97. McQuiston T, Luberto C, Del Poeta M. Role of sphingosine-1phosphate (S1P) and S1P receptor 2 in the phagocytosis of Cryptococcus neoformans by alveolar macrophages. Microbiology. (2011) 157:1416-27. doi: 10.1099/mic.0.045989-0

98. Hou J, Chen Q, Zhang K, Cheng B, Xie G, Wu X, et al. Sphingosine 1phosphate receptor 2 signaling suppresses macrophage phagocytosis and impairs host defense against sepsis. Anesthesiology. (2015) 123:409-22. doi: 10.1097/ALN.0000000000000725

99. Kuehnel MP, Rybin V, Anand PK, Anes E, Griffiths G. Lipids regulate P2X7receptor-dependent actin assembly by phagosomes via ADP translocation and ATP synthesis in the phagosome lumen. J Cell Sci. (2009) 122:499-504. doi: $10.1242 /$ jcs.034199

100. Kuehnel MP, Reiss M, Anand PK, Treede I, Holzer D, Hoffmann E, et al. Sphingosine-1-phosphate receptors stimulate macrophage plasmamembrane actin assembly via ADP release, ATP synthesis and P2X7R activation. J Cell Sci. (2009) 122:505-12. doi: 10.1242/jcs.034207

101. Anes E, Kuhnel MP, Bos E, Moniz-Pereira J, Habermann A, Griffiths G. Selected lipids activate phagosome actin assembly and maturation resulting in killing of pathogenic mycobacteria. Nat Cell Biol. (2003) 5:793-802. doi: $10.1038 /$ ncb1036
102. Garg SK, Volpe E, Palmieri G, Mattei M, Galati D, Martino A, et al. Sphingosine 1-phosphate induces antimicrobial activity both in vitro and in vivo. J Infect Dis. (2004) 189:2129-38. doi: 10.1086/386286

103. Gutierrez MG, Gonzalez AP, Anes E, Griffiths G. Role of lipids in killing mycobacteria by macrophages: evidence for NF-kappaB-dependent and -independent killing induced by different lipids. Cell Microbiol. (2009) 11:406-20. doi: 10.1111/j.1462-5822.2008.01263.x

104. Hou J, Chen Q, Wu X, Zhao D, Reuveni H, Licht T, et al. S1PR3 signaling drives bacterial killing and is required for survival in bacterial sepsis. Am J Respir Crit Care Med. (2017) 196:1559-70. doi: 10.1164/rccm.201701-0241OC

105. Prakash H, Luth A, Grinkina N, Holzer D, Wadgaonkar R, Gonzalez AP, et al. Sphingosine kinase-1 (SphK-1) regulates Mycobacterium smegmatis infection in macrophages. PLoS ONE. (2010) 5:e10657. doi: 10.1371/journal.pone.0010657

106. Malik ZA, Thompson CR, Hashimi S, Porter B, Iyer SS, Kusner DJ. Cutting edge: Mycobacterium tuberculosis blocks $\mathrm{Ca} 2+$ signaling and phagosome maturation in human macrophages via specific inhibition of sphingosine kinase. J Immunol. (2003) 170:2811-5. doi: 10.4049/jimmunol.170.6.2811

107. Thompson CR, Iyer SS, Melrose N, VanOosten R, Johnson $\mathrm{K}$, Pitson SM, et al. Sphingosine kinase 1 (SK1) is recruited to nascent phagosomes in human macrophages: inhibition of SK1 translocation by Mycobacterium tuberculosis. J Immunol. (2005) 174:3551-61. doi: 10.4049/jimmunol.174.6.3551

108. McQuiston T, Luberto C, Del Poeta M. Role of host sphingosine kinase 1 in the lung response against Cryptococcosis. Infect Immun. (2010) 78:2342-52. doi: 10.1128/IAI.01140-09

109. Arish M, Husein A, Ali R, Tabrez S, Naz F, Ahmad MZ, et al. Sphingosine-1phosphate signaling in Leishmania donovani infection in macrophages. PLoS Negl Trop Dis. (2018) 12:e0006647. doi: 10.1371/journal.pntd.0006647

110. Custodio R, McLean CJ, Scott AE, Lowther J, Kennedy A, Clarke DJ, et al. Characterization of secreted sphingosine-1-phosphate lyases required for virulence and intracellular survival of Burkholderia pseudomallei. Mol Microbiol. (2016) 102:1004-19. doi: 10.1111/mmi.13531

111. Rolando M, Escoll P, Nora T, Botti J, Boitez V, Bedia C, et al. Legionella pneumophila S1P-lyase targets host sphingolipid metabolism and restrains autophagy. Proc Natl Acad Sci USA. (2016) 113:1901-6. doi: 10.1073/pnas.1522067113

112. Black RA, Rauch CT, Kozlosky CJ, Peschon JJ, Slack JL, Wolfson MF, et al. A metalloproteinase disintegrin that releases tumour-necrosis factor-alpha from cells. Nature. (1997) 385:729-33. doi: 10.1038/385729a0

113. Schott J, Reitter S, Philipp J, Haneke K, Schafer H, Stoecklin G. Translational regulation of specific mRNAs controls feedback inhibition and survival during macrophage activation. PLoS Genet. (2014) 10:e1004368. doi: 10.1371/journal.pgen.1004368

114. Alvarez SE, Harikumar KB, Hait NC, Allegood J, Strub GM, Kim EY, et al. Sphingosine-1-phosphate is a missing cofactor for the E3 ubiquitin ligase TRAF2. Nature. (2010) 465:1084-8. doi: 10.1038/nature09128

115. Xia P, Wang L, Moretti PA, Albanese N, Chai F, Pitson SM, et al. Sphingosine kinase interacts with TRAF2 and dissects tumor necrosis factor-alpha signaling. J Biol Chem. (2002) 277:7996-8003. doi: 10.1074/jbc.M111423200

116. Harikumar KB, Yester JW, Surace MJ, Oyeniran C, Price MM, Huang WC, et al. K63-linked polyubiquitination of transcription factor IRF1 is essential for IL-1-induced production of chemokines CXCL10 and CCL5. Nat Immunol. (2014) 15:231-8. doi: 10.1038/ni.2810

117. Pchejetski D, Nunes J, Coughlan K, Lall H, Pitson SM, Waxman J, et al. The involvement of sphingosine kinase 1 in LPS-induced Toll-like receptor 4-mediated accumulation of HIF-1alpha protein, activation of ASK1 and production of the pro-inflammatory cytokine IL-6. Immunol Cell Biol. (2011) 89:268-74. doi: 10.1038/icb.2010.91

118. Nayak D, Huo Y, Kwang WX, Pushparaj PN, Kumar SD, Ling EA, et al. Sphingosine kinase 1 regulates the expression of proinflammatory cytokines and nitric oxide in activated microglia. Neuroscience. (2010) 166:132-44. doi: 10.1016/j.neuroscience.2009.12.020

119. Hammad SM, Crellin HG, Wu BX, Melton J, Anelli V, Obeid LM. Dual and distinct roles for sphingosine kinase 1 and sphingosine 1 phosphate in the response to inflammatory stimuli in RAW 
macrophages. Prostaglandins Other Lipid Mediat. (2008) 85:107-14. doi: 10.1016/j.prostaglandins.2007.11.002

120. Jin J, Lu Z, Li Y, Ru JH, Lopes-Virella MF, Huang Y. LPS and palmitate synergistically stimulate sphingosine kinase 1 and increase sphingosine 1 phosphate in RAW264.7 macrophages. J Leukoc Biol. (2018) 104:843-53. doi: 10.1002/JLB.3A0517-188RRR

121. Baker DA, Barth J, Chang R, Obeid LM, Gilkeson GS. Genetic sphingosine kinase 1 deficiency significantly decreases synovial inflammation and joint erosions in murine TNF-alpha-induced arthritis. J Immunol. (2010) 185:2570-9. doi: 10.4049/jimmunol.1000644

122. Michaud J, Kohno M, Proia RL, Hla T. Normal acute and chronic inflammatory responses in sphingosine kinase 1 knockout mice. FEBS Lett. (2006) 580:4607-12. doi: 10.1016/j.febslet.2006.07.035

123. Xiong Y, Lee HJ, Mariko B, Lu YC, Dannenberg AJ, Haka AS, et al. Sphingosine kinases are not required for inflammatory responses in macrophages. J Biol Chem. (2013) 288:32563-73. doi: $10.1074 /$ jbc.M113.483750

124. Liang J, Nagahashi M, Kim EY, Harikumar KB, Yamada A, Huang WC, et al. Sphingosine-1-phosphate links persistent STAT3 activation, chronic intestinal inflammation, and development of colitis-associated cancer. Cancer Cell. (2013) 23:107-20. doi: 10.1016/j.ccr.2012.11.013

125. Ghosh M, Thangada S, Dasgupta O, Khanna KM, Yamase HT, Kashgarian M, et al. Cell-intrinsic sphingosine kinase 2 promotes macrophage polarization and renal inflammation in response to unilateral ureteral obstruction. PLoS ONE. (2018) 13:e0194053. doi: 10.1371/journal.pone.0194053

126. Hornuss C, Hammermann R, Fuhrmann M, Juergens UR, Racke K. Human and rat alveolar macrophages express multiple EDG receptors. Eur $J$ Pharmacol. (2001) 429:303-8. doi: 10.1016/S0014-2999(01)01329-2

127. Lee H, Liao JJ, Graeler M, Huang MC, Goetzl EJ. Lysophospholipid regulation of mononuclear phagocytes. Biochim Biophys Acta. (2002) 1582:175-7. doi: 10.1016/S1388-1981(02)00153-1

128. Yang J, Yang L, Tian L, Ji X, Yang L, Li L. Sphingosine 1-Phosphate (S1P)/S1P receptor $/ 3$ axis promotes inflammatory M1 polarization of bone marrow-derived monocyte/macrophage via G(alpha)i/o/PI3K/JNK pathway. Cell Physiol Biochem. (2018) 49:1677-93. doi: 10.1159/000493611

129. Gaire BP, Song MR, Choi JW. Sphingosine 1-phosphate receptor subtype 3 (S1P3) contributes to brain injury after transient focal cerebral ischemia via modulating microglial activation and their M1 polarization. J Neuroinflamm. (2018) 15:284. doi: 10.1186/s12974-018-1323-1

130. Heo JY, Im DS. Pro-inflammatory role of S1P3 in macrophages. Biomol Ther. (2019) 27:373-80. doi: 10.4062/biomolther.2018.215

131. Netea MG, van de Veerdonk FL, van der Meer JW, Dinarello CA, Joosten LA. Inflammasome-independent regulation of IL-1-family cytokines. Annu Rev Immunol. (2015) 33:49-77. doi: 10.1146/annurev-immunol-032414-112306

132. Weichand B, Popp R, Dziumbla S, Mora J, Strack E, Elwakeel E, et al. S1PR1 on tumor-associated macrophages promotes lymphangiogenesis and metastasis via NLRP3/IL-1beta. J Exp Med. (2017) 214:2695-713. doi: 10.1084/jem.20160392

133. Burow P, Klapperstuck M, Markwardt F. Activation of ATP secretion via volume-regulated anion channels by sphingosine-1phosphate in RAW macrophages. Pflugers Arch. (2015) 467:1215-26. doi: 10.1007/s00424-014-1561-8

134. Zhao S, Gong Z, Zhou J, Tian C, Gao Y, Xu C, et al. Deoxycholic acid triggers NLRP3 inflammasome activation and aggravates DSS-induced colitis in mice. Front Immunol. (2016) 7:536. doi: 10.3389/fimmu.2016.00536

135. Skoura A, Michaud J, Im DS, Thangada S, Xiong Y, Smith JD, et al. Sphingosine-1-phosphate receptor-2 function in myeloid cells regulates vascular inflammation and atherosclerosis. Arterioscler Thromb Vasc Biol. (2011) 31:81-5. doi: 10.1161/ATVBAHA.110. 213496

136. Syed SN, Jung M, Weigert A, Brune B. S1P Provokes tumor lymphangiogenesis via macrophage-derived mediators such as IL1beta or Lipocalin-2. Mediators Inflamm. (2017) 2017:7510496. doi: 10.1155/2017/7510496

137. Hughes JE, Srinivasan S, Lynch KR, Proia RL, Ferdek P, Hedrick CC. Sphingosine-1-phosphate induces an antiinflammatory phenotype in macrophages. Circ Res. (2008) 102:950-8. doi: 10.1161/CIRCRESAHA.107.170779
138. Weigert A, Tzieply N, von Knethen A, Johann AM, Schmidt H, Geisslinger $\mathrm{G}$, et al. Tumor cell apoptosis polarizes macrophages role of sphingosine-1phosphate. Mol Biol Cell. (2007) 18:3810-9. doi: 10.1091/mbc.e06-12-1096

139. Cao C, Gao Y, Li Y, Antalis TM, Castellino FJ, Zhang L. The efficacy of activated protein $\mathrm{C}$ in murine endotoxemia is dependent on integrin CD11b. J Clin Invest. (2010) 120:1971-80. doi: 10.1172/JCI40380

140. Duenas AI, Aceves M, Fernandez-Pisonero I, Gomez C, Orduna A, Crespo MS, et al. Selective attenuation of Toll-like receptor 2 signalling may explain the atheroprotective effect of sphingosine 1-phosphate. Cardiovasc Res. (2008) 79:537-44. doi: 10.1093/cvr/cvn087

141. Zhao S, Adebiyi MG, Zhang Y, Couturier JP, Fan X, Zhang H, et al. Sphingosine-1-phosphate receptor 1 mediates elevated IL-6 signaling to promote chronic inflammation and multitissue damage in sickle cell disease. FASEB J. (2018) 32:2855-65. doi: 10.1096/fj.201600788RR

142. Johann AM, Weigert A, Eberhardt W, Kuhn AM, Barra V, von Knethen A, et al. Apoptotic cell-derived sphingosine-1-phosphate promotes HuRdependent cyclooxygenase-2 mRNA stabilization and protein expression. $J$ Immunol. (2008) 180:1239-48. doi: 10.4049/jimmunol.180.2.1239

143. Brecht K, Weigert A, Hu J, Popp R, Fisslthaler B, Korff T, et al. Macrophages programmed by apoptotic cells promote angiogenesis via prostaglandin E2. FASEB J. (2011) 25:2408-17. doi: 10.1096/fj.10-179473

144. Barra V, Kuhn A-M, von Knethen A, Weigert A, Bruene B. Apoptotic cellderived factors induce arginase II expression in murine macrophages by activating ERK5/CREB. Cell Mol Life Sci. (2011) 68:1815-27. doi: 10.1007/s00018-010-0537-x

145. Jiang LI, Collins J, Davis R, Lin KM, DeCamp D, Roach T, et al. Use of a CAMP BRET sensor to characterize a novel regulation of cAMP by the sphingosine 1-phosphate/G13 pathway. J Biol Chem. (2007) 282:10576-84. doi: 10.1074/jbc.M609695200

146. Bystrom J, Evans I, Newson J, Stables M, Toor I, van Rooijen N, et al. Resolution-phase macrophages possess a unique inflammatory phenotype that is controlled by cAMP. Blood. (2008) 112:4117-27. doi: 10.1182/blood-2007-12-129767

147. Ley S, Weigert A, Weichand B, Henke N, Mille-Baker B, Janssen RAJ, et al. The role of TRKA signaling in IL-10 production by apoptotic tumor cell-activated macrophages. Oncogene. (2013) 32:631-40. doi: $10.1038 /$ onc. 2012.77

148. Balkwill F, Mantovani A. Inflammation and cancer: back to Virchow? Lancet. (2001) 357:539-45. doi: 10.1016/S0140-6736(00)04046-0

149. Swann JB, Smyth MJ. Immune surveillance of tumors. J Clin Invest. (2007) 117:1137-46. doi: 10.1172/JCI31405

150. Schreiber RD, Old LJ, Smyth MJ, Cancer immunoediting: integrating immunity's roles in cancer suppression and promotion. Science. (2011) 331:1565-70. doi: 10.1126/science. 1203486

151. Aras S, Zaidi MR. TAMeless traitors: macrophages in cancer progression and metastasis. Br J Cancer. (2017) 117:1583-91. doi: 10.1038/bjc.2017.356

152. Zheng X, Turkowski K, Mora J, Brune B, Seeger W, Weigert A, et al. Redirecting tumor-associated macrophages to become tumoricidal effectors as a novel strategy for cancer therapy. Oncotarget. (2017) 8:48436-52. doi: $10.18632 /$ oncotarget.17061

153. Fridman WH, Zitvogel L, Sautes-Fridman C, Kroemer G. The immune contexture in cancer prognosis and treatment. Nat Rev Clin Oncol. (2017) 14:717-34. doi: 10.1038/nrclinonc.2017.101

154. Pyne NJ, Tonelli F, Lim KG, Long JS, Edwards J, Pyne S. Sphingosine 1-phosphate signalling in cancer. Biochem Soc Trans. (2012) 40:94-100. doi: 10.1042/BST20110602

155. Mrad M, Imbert C, Garcia V, Rambow F, Therville N, Carpentier S, et al. Downregulation of sphingosine kinase-1 induces protective tumor immunity by promoting M1 macrophage response in melanoma. Oncotarget. (2016) 7:71873-86. doi: 10.18632/oncotarget.12380

156. Furuya H, Tamashiro PM, Shimizu Y, Iino K, Peres R, Chen R, et al. Sphingosine Kinase 1 expression in peritoneal macrophages is required for colon carcinogenesis. Carcinogenesis. (2017) 38:1218-27. doi: 10.1093/carcin/bgx104

157. Ader I, Malavaud B, Cuvillier $O$. When the sphingosine kinase 1/sphingosine 1-phosphate pathway meets hypoxia signaling: new targets for cancer therapy. Cancer Res. (2009) 69:3723-6. doi: 10.1158/0008-5472.CAN-09-0389 
158. Bouquerel P, Gstalder C, Muller D, Laurent J, Brizuela L, Sabbadini RA, et al. Essential role for SphK1/S1P signaling to regulate hypoxia-inducible factor 2alpha expression and activity in cancer. Oncogenesis. (2016) 5:e209. doi: 10.1038/oncsis.2016.13

159. Gstalder C, Ader I, Cuvillier O. FTY720 (Fingolimod) inhibits HIF1 and HIF2 signaling, promotes vascular remodeling, and chemosensitizes in renal cell carcinoma animal model. Mol Cancer Ther. (2016) 15:2465-74. doi: 10.1158/1535-7163.MCT-16-0167

160. Herr B, Zhou J, Werno C, Menrad H, Namgaladze D, Weigert A, et al. The supernatant of apoptotic cells causes transcriptional activation of hypoxia-inducible factor-1alpha in macrophages via sphingosine-1phosphate and transforming growth factor-beta. Blood. (2009) 114:2140-8. doi: 10.1182/blood-2009-01-201889

161. Du W, Takuwa N, Yoshioka K, Okamoto Y, Gonda K, Sugihara K, et al. S1P(2), the G protein-coupled receptor for sphingosine-1-phosphate, negatively regulates tumor angiogenesis and tumor growth in vivo in mice. Cancer Res. (2010) 70:772-81. doi: 10.1158/0008-5472.CAN-09-2722

162. Moore KJ, Sheedy FJ, Fisher EA. Macrophages in atherosclerosis: a dynamic balance. Nat Rev Immunol. (2013) 13:709-21. doi: 10.1038/nri3520

163. Okajima F. Plasma lipoproteins behave as carriers of extracellular sphingosine 1-phosphate: is this an atherogenic mediator or an antiatherogenic mediator? Biochim Biophys Acta. (2002) 1582:132-7. doi: 10.1016/S1388-1981(02)00147-6

164. Catapano AL, Pirillo A, Bonacina F, Norata GD. HDL in innate and adaptive immunity. Cardiovasc Res. (2014) 103:372-83. doi: 10.1093/cvr/ cvu150

165. Christoffersen C, Obinata H, Kumaraswamy SB, Galvani S, Ahnstrom J, Sevvana M, et al. Endothelium-protective sphingosine-1-phosphate provided by HDL-associated apolipoprotein M. Proc Natl Acad Sci USA. (2011) 108:9613-8. doi: 10.1073/pnas.1103187108

166. Arkensteijn BW, Berbee JF, Rensen PC, Nielsen LB, Christoffersen C. The apolipoprotein $\mathrm{m}$-sphingosine-1-phosphate axis: biological relevance in lipoprotein metabolism, lipid disorders and atherosclerosis. Int J Mol Sci. (2013) 14:4419-31. doi: 10.3390/ijms14034419

167. Sattler K, Levkau B. Sphingosine-1-phosphate as a mediator of high-density lipoprotein effects in cardiovascular protection. Cardiovasc Res. (2009) 82:201-11. doi: 10.1093/cvr/cvp070

168. Kurano M, Tsukamoto K, Ohkawa R, Hara M, Iino J, Kageyama Y, et al. Liver involvement in sphingosine 1-phosphate dynamism revealed by adenoviral hepatic overexpression of apolipoprotein M. Atherosclerosis. (2013) 229:1029. doi: 10.1016/j.atherosclerosis.2013.04.024

169. Kimura T, Tomura H, Mogi C, Kuwabara A, Damirin A, Ishizuka T, et al. Role of scavenger receptor class B type I and sphingosine 1phosphate receptors in high density lipoprotein-induced inhibition of adhesion molecule expression in endothelial cells. J Biol Chem. (2006) 281:37457-67. doi: 10.1074/jbc.M605823200

170. Levkau B. HDL-S1P: cardiovascular functions, disease-associated alterations, and therapeutic applications. Front Pharmacol. (2015) 6:243. doi: 10.3389/fphar.2015.00243

171. Kurano M, Yatomi Y. Sphingosine 1-phosphate and atherosclerosis. $J$ Atheroscler Thromb. (2018) 25:16-26. doi: 10.5551/jat.RV17010

172. Keul P, Lucke S, von Wnuck Lipinski K, Bode C, Graler M, Heusch G, et al. Sphingosine-1-phosphate receptor 3 promotes recruitment of monocyte/macrophages in inflammation and atherosclerosis. Circ Res. (2011) 108:314-23. doi: 10.1161/CIRCRESAHA.110.235028

173. Nofer JR, Bot M, Brodde M, Taylor PJ, Salm P, Brinkmann $\mathrm{V}$, et al. FTY720, a synthetic sphingosine 1 phosphate analogue, inhibits development of atherosclerosis in low-density lipoprotein receptor-deficient mice. Circulation. (2007) 115:501-8. doi: 10.1161/CIRCULATIONAHA.106.641407

174. Poti F, Gualtieri F, Sacchi S, Weissen-Plenz G, Varga G, Brodde M, et al. KRP-203, sphingosine 1-phosphate receptor type 1 agonist, ameliorates atherosclerosis in LDL-R-/- mice. Arterioscler Thromb Vasc Biol. (2013) 33:1505-12. doi: 10.1161/ATVBAHA.113.301347

175. Park SJ, Lee KP, Kang S, Lee J, Sato K, Chung HY, et al. Sphingosine 1-phosphate induced anti-atherogenic and atheroprotective M2 macrophage polarization through IL-4. Cell Signal. (2014) 26:2249-58. doi: 10.1016/j.cellsig.2014.07.009
176. Vaidya M, Jentsch JA, Peters S, Keul P, Weske S, Graler MH, et al. Regulation of ABCA1-mediated cholesterol efflux by sphingosine-1-phosphate signaling in macrophages. J Lipid Res. (2019) 60:506-515. doi: 10.1194/jlr.M088443

177. Brulhart-Meynet MC, Braunersreuther V, Brinck J, Montecucco F, Prost JC, Thomas A, et al. Improving reconstituted HDL composition for efficient post-ischemic reduction of ischemia reperfusion injury. PLoS ONE. (2015) 10:e0119664. doi: 10.1371/journal.pone.0119664

178. Sattler K, Graler M, Keul P, Weske S, Reimann CM, Jindrova H, et al. Defects of high-density lipoproteins in coronary artery disease caused by low sphingosine-1-phosphate content: correction by sphingosine-1-phosphate-loading. J Am Coll Cardiol. (2015) 66:1470-85. doi: 10.1016/j.jacc.2015.07.057

179. Keul P, Polzin A, Kaiser K, Graler M, Dannenberg L, Daum G, et al. Potent anti-inflammatory properties of HDL in vascular smooth muscle cells mediated by HDL-S1P and their impairment in coronary artery disease due to lower HDL-S1P: a new aspect of HDL dysfunction and its therapy. FASEB J. (2019) 33:1482-95. doi: 10.1096/fj.201801245R

180. Kurano M, Hara M, Nojiri T, Ikeda H, Tsukamoto K, Yatomi Y. Resveratrol exerts a biphasic effect on apolipoprotein M. Br J Pharmacol. (2016) 173:22233. doi: 10.1111/bph. 13360

181. Wynn TA, Vannella KM. Macrophages in tissue repair, regeneration, and fibrosis. Immunity. (2016) 44:450-62. doi: 10.1016/j.immuni.2016.02.015

182. Wick G, Grundtman C, Mayerl C, Wimpissinger TF, Feichtinger J, Zelger B, et al. The immunology of fibrosis. Annu Rev Immunol. (2013) 31:107-35. doi: 10.1146/annurev-immunol-032712-095937

183. Murray LA. Editorial: the cell types of fibrosis. Front Pharmacol. (2015) 6:311. doi: 10.3389/fphar.2015.00311

184. Lech M, Anders HJ. Macrophages and fibrosis: How resident and infiltrating mononuclear phagocytes orchestrate all phases of tissue injury and repair. Biochim Biophys Acta. (2013) 1832:989-97. doi: 10.1016/j.bbadis.2012.12.001

185. Zhang L, Wang Y, Wu G, Xiong W, Gu W, Wang CY. Macrophages: friend or foe in idiopathic pulmonary fibrosis? Respir Res. (2018) 19:170. doi: 10.1186/s12931-018-0864-2

186. Yao Y, Wang Y, Zhang Z, He L, Zhu J, Zhang M, et al. Chop deficiency protects mice against bleomycin-induced pulmonary fibrosis by attenuating M2 macrophage production. Mol Ther. (2016) 24:915-25. doi: $10.1038 / \mathrm{mt} .2016 .36$

187. Huang LS, Natarajan V. Sphingolipids in pulmonary fibrosis. Adv Biol Regul. (2015) 57:55-63. doi: 10.1016/j.jbior.2014.09.008

188. Milara J, Navarro R, Juan G, Peiro T, Serrano A, Ramon M, et al. Sphingosine1-phosphate is increased in patients with idiopathic pulmonary fibrosis and mediates epithelial to mesenchymal transition. Thorax. (2012) 67:147-56. doi: 10.1136/thoraxjnl-2011-200026

189. Kono Y, Nishiuma T, Nishimura Y, Kotani Y, Okada T, Nakamura S, et al. Sphingosine kinase 1 regulates differentiation of human and mouse lung fibroblasts mediated by TGF-beta1. Am J Respir Cell Mol Biol. (2007) 37:395404. doi: $10.1165 / \mathrm{rcmb} .2007-0065 \mathrm{OC}$

190. Zhao J, Okamoto Y, Asano Y, Ishimaru K, Aki S, Yoshioka K, et al. Sphingosine-1-phosphate receptor-2 facilitates pulmonary fibrosis through potentiating IL-13 pathway in macrophages. PLoS ONE. (2018) 13:e0197604. doi: 10.1371/journal.pone.0197604

191. Li C, Jiang X, Yang L, Liu X, Yue S, Li L. Involvement of sphingosine 1phosphate (SIP)/S1P3 signaling in cholestasis-induced liver fibrosis. Am J Pathol. (2009) 175:1464-72. doi: 10.2353/ajpath.2009.090037

192. Yang L, Yue S, Yang L, Liu X, Han Z, Zhang Y, et al. Sphingosine kinase/sphingosine 1-phosphate (S1P)/S1P receptor axis is involved in liver fibrosis-associated angiogenesis. J Hepatol. (2013) 59:114-23. doi: 10.1016/j.jhep.2013.02.021

193. Lan T, Li C, Yang G, Sun Y, Zhuang L, Ou Y, et al. Sphingosine kinase 1 promotes liver fibrosis by preventing miR-19b-3p-mediated inhibition of CCR2. Hepatology. (2018) 68:1070-86. doi: 10.1002/hep.29885

194. Ni HF, Chen JF, Zhang MH, Pan MM, Zhang JD, Liu H, et al. FTY720 attenuates tubulointerstitial inflammation and fibrosis in subtotally nephrectomized rats. Ren Fail. (2013) 35:996-1004. doi: 10.3109/0886022X.2013.809006

195. Weinberger T, Schulz C. Myocardial infarction: a critical role of macrophages in cardiac remodeling. Front Physiol. (2015) 6:107. doi: 10.3389/fphys.2015.00107 
196. Mouton AJ, DeLeon-Pennell KY, Rivera Gonzalez OJ, Flynn ER, Freeman TC, Saucerman JJ, et al. Mapping macrophage polarization over the myocardial infarction time continuum. Basic Res Cardiol. (2018) 113:26. doi: 10.1007/s00395-018-0686-x

197. Kanazawa M, Ninomiya I, Hatakeyama M, Takahashi T, Shimohata T. Microglia and monocytes/macrophages polarization reveal novel therapeutic mechanism against stroke. Int J Mol Sci. (2017) 18:E2135. doi: $10.3390 /$ ijms 18102135

198. Nielsen MM, Lambertsen KL, Clausen BH, Meyer M, Bhandari DR, Larsen ST, et al. Mass spectrometry imaging of biomarker lipids for phagocytosis and signalling during focal cerebral ischaemia. Sci Rep. (2016) 6:39571. doi: $10.1038 /$ srep39571

199. Czech B, Pfeilschifter W, Mazaheri-Omrani N, Strobel MA, Kahles T, Neumann-Haefelin $\mathrm{T}$, et al. The immunomodulatory sphingosine 1phosphate analog FTY720 reduces lesion size and improves neurological outcome in a mouse model of cerebral ischemia. Biochem Biophys Res Commun. (2009) 389:251-6. doi: 10.1016/j.bbrc.2009.08.142

200. Wei Y, Yemisci M, Kim HH, Yung LM, Shin HK, Hwang SK, et al. Fingolimod provides long-term protection in rodent models of cerebral ischemia. Ann Neurol. (2011) 69:119-29. doi: 10.1002/ana.22186

201. Xie B, Shen J, Dong A, Rashid A, Stoller G, Campochiaro PA. Blockade of sphingosine-1-phosphate reduces macrophage influx and retinal and choroidal neovascularization. J Cell Physiol. (2009) 218:192-8. doi: $10.1002 /$ jcp. 21588

202. Ito T, Kuriyama N, Kato H, Matsuda A, Mizuno S, Usui M, et al. Sinusoidal protection by sphingosine-1-phosphate receptor 1 agonist in liver ischemia-reperfusion injury. J Surg Res. (2018) 222:139-52. doi: 10.1016/j.jss.2017.09.048

203. Lien YH, Yong KC, Cho C, Igarashi S, Lai LW. S1P(1)-selective agonist, SEW2871, ameliorates ischemic acute renal failure. Kidney Int. (2006) 69:1601-8. doi: 10.1038/sj.ki.5000360

204. Bajwa A, Jo SK, Ye H, Huang L, Dondeti KR, Rosin DL, et al. Activation of sphingosine-1-phosphate 1 receptor in the proximal tubule protects against ischemia-reperfusion injury. J Am Soc Nephrol. (2010) 21:955-65. doi: 10.1681/ASN.2009060662

205. Bajwa A, Rosin DL, Chroscicki P, Lee S, Dondeti K, Ye H, et al. Sphingosine 1-phosphate receptor-1 enhances mitochondrial function and reduces cisplatin-induced tubule injury. J Am Soc Nephrol. (2015) 26:908-25. doi: 10.1681/ASN.2013121351

206. Sola A, Weigert A, Jung $M$, Vinuesa E, Brecht $K$, Weis $N$, et al. Sphingosine-1-phosphate signalling induces the production of Lcn-2 by macrophages to promote kidney regeneration. J Pathol. (2011) 225:597-608. doi: $10.1002 /$ path.2982

207. Otaka N, Shibata R, Ohashi K, Uemura Y, Kambara T, Enomoto T, et al. Myonectin is an exercise-induced myokine that protects the heart from ischemia-reperfusion injury. Circ Res. (2018) 123:1326-38. doi: 10.1161/CIRCRESAHA.118.313777

208. Schneider-Schaulies J, Schneider-Schaulies S. Sphingolipids in viral infection. Biol Chem. (2015) 396:585-95. doi: 10.1515/hsz-2014-0273

209. Baker JE, Boudreau RM, Seitz AP, Caldwell CC, Gulbins E, Edwards MJ. Sphingolipids and innate immunity: a new approach to infection in the post-antibiotic era? Surg Infect. (2018) 19:792-803. doi: 10.1089/sur.2018.187

210. Sharma L, Prakash H. Sphingolipids are dual specific drug targets for the management of pulmonary infections: perspective. Front Immunol. (2017) 8:378. doi: 10.3389/fimmu.2017.00378

211. Vettorazzi S, Bode C, Dejager L, Frappart L, Shelest E, Klassen C, et al. Glucocorticoids limit acute lung inflammation in concert with inflammatory stimuli by induction of SphK1. Nat Commun. (2015) 6:7796. doi: $10.1038 /$ ncomms 8796

212. Gutbier B, Schonrock SM, Ehrler C, Haberberger R, Dietert K, Gruber $\mathrm{AD}$, et al. Sphingosine kinase 1 regulates inflammation and contributes to acute lung injury in pneumococcal pneumonia via the sphingosine-1-phosphate receptor 2. Crit Care Med. (2018) 46:e258-67. doi: 10.1097/CCM.0000000000002916

213. Zemann B, Urtz N, Reuschel R, Mechtcheriakova D, Bornancin F, Badegruber R, et al. Normal neutrophil functions in sphingosinekinase type 1 and 2 knockout mice. Immunol Lett. (2007) 109:56-63. doi: 10.1016/j.imlet.2007.01.001

214. Murphy CT, Hall LJ, Hurley G, Quinlan A, MacSharry J, Shanahan F, et al. The sphingosine-1-phosphate analogue FTY720 impairs mucosal immunity and clearance of the enteric pathogen Citrobacter rodentium. Infect Immun. (2012) 80:2712-23. doi: 10.1128/IAI.06319-11

215. Das A, Segar CE, Hughley BB, Bowers DT, Botchwey EA. The promotion of mandibular defect healing by the targeting of S1P receptors and the recruitment of alternatively activated macrophages. Biomaterials. (2013) 34:9853-62. doi: 10.1016/j.biomaterials.2013.08.015

216. Grimm M, Tischner D, Troidl K, Albarran Juarez J, Sivaraj KK, Ferreiros Bouzas $\mathrm{N}$, et al. S1P2/G12/13 signaling negatively regulates macrophage activation and indirectly shapes the atheroprotective B1-cell population. Arterioscler Thromb Vasc Biol. (2016) 36:37-48. doi: 10.1161/ATVBAHA.115.306066

217. Olesch C, Ringel C, Brune B, Weigert A. Beyond immune cell migration: the emerging role of the sphingosine-1-phosphate receptor S1PR4 as a modulator of innate immune cell activation. Mediators Inflamm. (2017) 2017:6059203. doi: 10.1155/2017/6059203

218. Schulze T, Golfier S, Tabeling C, Rabel K, Graler MH, Witzenrath M, et al. Sphingosine-1-phospate receptor 4 (S1P) deficiency profoundly affects dendritic cell function and TH17-cell differentiation in a murine model. FASEB J. (2011) 25:4024-36. doi: 10.1096/fj.10-179028

219. Dillmann C, Ringel C, Ringleb J, Mora J, Olesch C, Fink AF, et al. S1PR4 signaling attenuates ILT 7 internalization to limit IFN-alpha production by human plasmacytoid dendritic cells. J Immunol. (2016) 196:1579-90. doi: 10.4049/jimmunol.1403168

220. Debien E, Mayol K, Biajoux V, Daussy C, De Aguero MG, Taillardet M, et al. S1PR5 is pivotal for the homeostasis of patrolling monocytes. Eur J Immunol. (2013) 43:1667-75. doi: 10.1002/eji.201343312

221. Hait NC, Allegood J, Maceyka M, Strub GM, Harikumar KB, Singh SK, et al. Regulation of histone acetylation in the nucleus by sphingosine-1-phosphate. Science. (2009) 325:1254-7. doi: 10.1126/science.1176709

222. Arts RJ, Joosten LA, Netea MG. Immunometabolic circuits in trained immunity. Semin Immunol. (2016) 28:425-30. doi: 10.1016/j.smim.2016.09.002

223. Park SJ, Im DS. Sphingosine 1-phosphate receptor modulators and drug discovery. Biomol Ther. (2017) 25:80-90. doi: 10.4062/biomolther.2016.160

224. Binnewies M, Roberts EW, Kersten K, Chan V, Fearon DF, Merad M, et al. Understanding the tumor immune microenvironment (TIME) for effective therapy. Nat Med. (2018) 24:541-50. doi: 10.1038/s41591-0180014-x

225. Pal SK, Drabkin HA, Reeves JA, Hainsworth JD, Hazel SE, Paggiarino $\mathrm{DA}$, et al. A phase 2 study of the sphingosine-1-phosphate antibody sonepcizumab in patients with metastatic renal cell carcinoma. Cancer. (2017) 123:576-82. doi: 10.1002/cncr.30393

226. Dickson MA, Carvajal RD, Merrill AH Jr, Gonen M, Cane LM, Schwartz GK. A phase I clinical trial of safingol in combination with cisplatin in advanced solid tumors. Clin Cancer Res. (2011) 17:2484-92. doi: 10.1158/1078-0432.CCR-10-2323

227. Britten CD, Garrett-Mayer E, Chin SH, Shirai K, Ogretmen B, Bentz TA, et al. A Phase I study of ABC294640, a first-in-class sphingosine kinase-2 inhibitor, in patients with advanced solid tumors. Clin Cancer Res. (2017) 23:4642-50. doi: 10.1158/1078-0432.CCR-16-2363

Conflict of Interest Statement: The authors declare that the research was conducted in the absence of any commercial or financial relationships that could be construed as a potential conflict of interest.

Copyright (c) 2019 Weigert, Olesch and Brüne. This is an open-access article distributed under the terms of the Creative Commons Attribution License (CC BY). The use, distribution or reproduction in other forums is permitted, provided the original author(s) and the copyright owner(s) are credited and that the original publication in this journal is cited, in accordance with accepted academic practice. No use, distribution or reproduction is permitted which does not comply with these terms. 